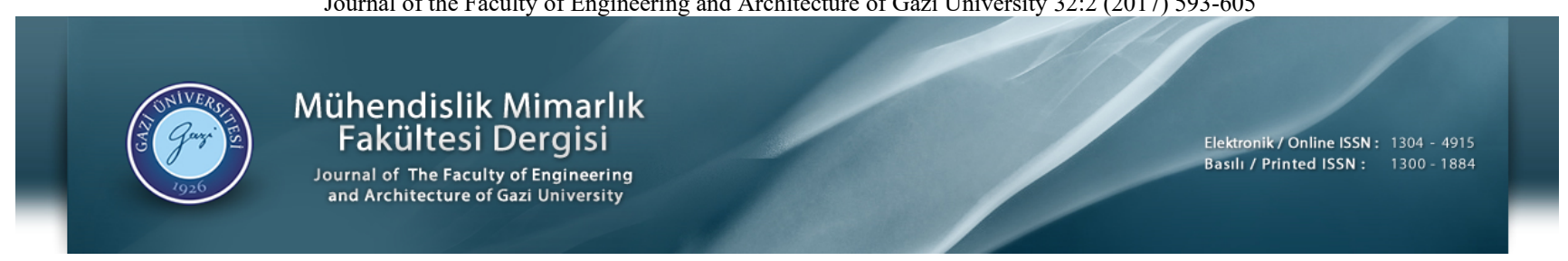

\title{
$\left[{ }^{18} \mathrm{~F}\right]$ Flor üretiminde hedef olarak kullanılan $\left[{ }^{18} \mathrm{O}\right] \mathrm{H}_{2} \mathrm{O}$ içindeki organik safsılzlkların giderimi
}

Nuray Yıldız*, Deniz Kıvrakdal Özkul

Ankara Üniversitesi, Mühendislik Fakültesi, Kimya Mühendisliği Bölümü, 06100, Tandoğan, Ankara, Türkiye

Ö N E Ç I K A N L A R

- $\quad{ }^{18} \mathrm{~F}$ üretiminde kullanılmış $\left[{ }^{18} \mathrm{O}\right] \mathrm{H}_{2} \mathrm{O}$ 'deki, organik safsızlıkların giderimi

- Giderim için ozonlama, ultrasonikasyon ve damıtma yöntemlerinin ayrı ayrı ve birleştirilmiş olarak örneklere uygulanmasi

- Saflaştırılmış $\left[{ }^{18} \mathrm{O}\right] \mathrm{H}_{2} \mathrm{O}$ ile $\left[{ }^{18} \mathrm{~F}\right]$ flor ve $\left[{ }^{18} \mathrm{~F}\right] \mathrm{FDG}$ üretimi

\begin{tabular}{|c|c|}
\hline & \\
\hline $\begin{array}{l}\text { Geliş: } 20.05 .2016 \\
\text { Kabul: } 27.01 .2017\end{array}$ & \multirow{5}{*}{ 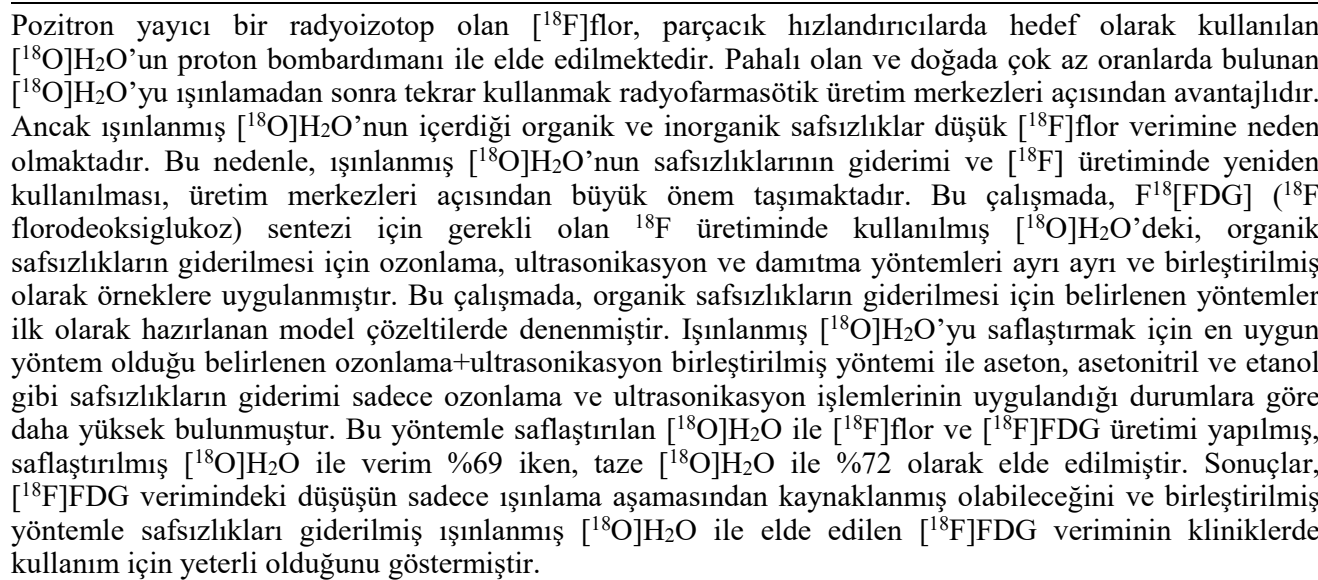 } \\
\hline DOI: & \\
\hline 10.17341/gazimmfd.3221 & \\
\hline Anahtar Kelimeler: & \\
\hline $\begin{array}{l}\text { ultrasonika } \\
\text { ozonlama }\end{array}$ & \\
\hline
\end{tabular}

\section{Purification of organic impurities from $\left[{ }^{18} \mathrm{O}\right] \mathrm{H}_{2} \mathrm{O}$ used for production of $\left[{ }^{18} \mathrm{~F}\right]$ fluoride as target material}

\section{H I G H L I G H T S}

- $\quad$ Removing of organic impurities from $\left[{ }^{18} \mathrm{O}\right] \mathrm{H}_{2} \mathrm{O}$ which is used as target water to produce $\left[{ }^{18} \mathrm{~F}\right]$ fluoride

- For removing, application of ozonolysis, ultrasonication, distillation methods separately and their combined forms

- Producing of $\left[{ }^{18} \mathrm{~F}\right]$ fluoride and ${ }^{18} \mathrm{~F}[\mathrm{FDG}]$ by purified $\left[{ }^{18} \mathrm{O}\right] \mathrm{H}_{2} \mathrm{O}$

Article Info

Received: 20.05.2016

Accepted: 27.01.2017

DOI:

10.17341/gazimmfd.322186

Keywords:

$\left[{ }^{18} \mathrm{O}\right] \mathrm{H}_{2} \mathrm{O}$

$\left[{ }^{18} \mathrm{~F}\right]$ fluoride, cyclotron,

ultrasonication,

ozonolysis

\section{ABSTRACT}

$\left[{ }^{18} \mathrm{~F}\right]$ fluoride, which is a positron emitting radioisotopes, is obtained by proton bombardment of $\left[{ }^{18} \mathrm{O}\right] \mathrm{H}_{2} \mathrm{O}$ as target material with accelarated protons in particle accelerators. Due to its high cost and very low natural abundance of ${ }^{18} \mathrm{O}^{\mathrm{O}} \mathrm{H}_{2} \mathrm{O}$, using of recyled ${ }^{18} \mathrm{O}^{\mathrm{O}} \mathrm{H}_{2} \mathrm{O}$ after irradiation is more advantageous for many radiopharmaceutical production centers. However, irradiated $\left[{ }^{18} \mathrm{O}\right] \mathrm{H}_{2} \mathrm{O}$ contains impurities which result in low $\left[{ }^{18} \mathrm{~F}\right]$ fluoride yields. So, purification of irradiated $\left[{ }^{18} \mathrm{O}\right] \mathrm{H}_{2} \mathrm{O}$ and using it for routin production of $\left[{ }^{18} \mathrm{~F}\right]$ is important. In this study, to remove organic impurities from $\left[{ }^{18} \mathrm{O}\right] \mathrm{H}_{2} \mathrm{O}$, which is used as target water to produce $\left[{ }^{18} \mathrm{~F}\right]$ fluoride for ${ }^{18} \mathrm{~F}[\mathrm{FDG}]\left({ }^{18} \mathrm{~F}\right.$ fluorodeoxyglucose) synthesis, ozonolysis, ultrasonication, distillation methods separately and their combined forms were applied to samples. The removing of acetone, acetonitrile and ethanol using a combination of ozonization+ultrasonication method, the more suitable method for purification of $\left[{ }^{18} \mathrm{O}\right] \mathrm{H}_{2} \mathrm{O}$, was found higher than that of ozonization and ultrasonication methods alone. While the yield of ${ }^{18} \mathrm{~F}$ [FDG] from fresh $\left[{ }^{18} \mathrm{O}\right] \mathrm{H}_{2} \mathrm{O}$ was $72 \%$, the yield of ${ }^{18} \mathrm{~F}$ [FDG] from purified $\left[{ }^{18} \mathrm{O}\right] \mathrm{H}_{2} \mathrm{O}$ was $69 \%$. The results showed that the decrease in ${ }^{18} \mathrm{~F}$ [FDG] yield may be attributed to irradiation step only and obtained yield from purified irradiated $\left[{ }^{18} \mathrm{O}\right] \mathrm{H}_{2} \mathrm{O}$ using combined purification method was sufficient for clinical purpose.

\footnotetext{
*Sorumlu Yazar/Corresponding author: nyildiz@eng.ankara.edu.tr / Tel: +90 3122033437
} 


\section{GİRIŞ̧ (INTRODUCTION)}

Radyofarmasötikler, nükleer tıpta teşhis ve tedavi amacıyla kullanılan ve hastaya en çok damar yoluyla verilen radyokimyasallardır. Görüntülemede kullanılan radyofarmasötikler genel olarak belli bir organ ya da dokuya yerleşmesini sağlayan bir biyokimyasal ajan ve yaydığı ışının kamera sistemleri ile belirlenerek tutulduğu dokunun izlenebilmesini sağlayan bir radyoaktif ajandan oluşmaktadır. Son yıllarda mannozla birleştirilerek elde edilen $\left[{ }^{18} \mathrm{~F}\right] \mathrm{FDG} \quad\left({ }^{18} \mathrm{~F}\right.$ radyoizotopu ile işaretlenmiş Florodeoksiglukoz), pozitron emisyon tomografi ile görüntülemede yaygın olarak kullanılan bir ${ }^{18} \mathrm{~F}$ radyofarmasötiğidir [1]. $\left[{ }^{18} \mathrm{~F}\right]$ Flor nükleer tıpta görüntüleme amacıyla kullanılan pozitron yayıcı bir radyoizotoptur. Bu izotop parçacık hızlandırıcılarda (siklotron) hedef olarak kullanılan ${ }^{18} \mathrm{O}$ 'ce zenginleştirilmiş suyun $\left(\left[{ }^{18} \mathrm{O}\right] \mathrm{H}_{2} \mathrm{O}\right.$, zenginleşme oranı \%95-97 olan) proton bombardımanı ile elde edilmektedir. Elde edilen $\left[{ }^{18} \mathrm{~F}\right]$ Flor bir kimyasal sentez işleminden sonra hastada görüntülenmesi hedeflenen organa gidebilecek kimyasal forma getirilir. Doğada \%0.2 oranında bulunan $\left[{ }^{18} \mathrm{O}\right] \mathrm{H}_{2} \mathrm{O}$ ticari olarak kademeli damıtma kolonlarında elde edilmektedir. $\left[{ }^{18} \mathrm{O} \mathrm{H}_{2} \mathrm{O}\right.$ pahalı olduğu için üretim merkezleri açısından yeni $\left[{ }^{18} \mathrm{O}\right] \mathrm{H}_{2} \mathrm{O}$ satın alma yerine 1şınlanmış suyu tekrar kullanmak daha avantajlıdır $[2,3]$. Gerek 1şınlama, gerek kimyasal sentez işlemleri ${ }^{18} \mathrm{O}$ 'ce zenginleştirilmiş suyun kirlenmesine [4] ve 1şınlanmış $\left[{ }^{18} \mathrm{O}\right] \mathrm{H}_{2} \mathrm{O}$ içindeki safsızlıklar ise $\left[{ }^{18} \mathrm{~F}\right]$ veriminin düşmesine neden olur [5]. Işınlanmış suyun, $\left[{ }^{18} \mathrm{O}\right] \mathrm{H}_{2} \mathrm{O}$, tekrar kullanılması içindeki organik (etanol, metanol, asetonitril) [2], inorganik ( $\left.\mathrm{K}^{+}, \mathrm{Na}^{+}, \mathrm{Cl}^{-} \mathrm{vb}\right)$ [2] ve radyonüklidik safsızlıkların [6] giderilmesi ile gerçekleşebilir. İnorganik (iyonik) safsızlıkları gidermede yaygin olarak katı faz ekstraksiyonu yöntemi kullanılmaktadır [7]. Araştırmacılar, 1şınlanmış $\left[{ }^{18} \mathrm{O}\right] \mathrm{H}_{2} \mathrm{O}$ içindeki organik safsılılıkları gidermek için, ozon [8] , damıtma[9] , UV ile oksidasyon[2], He gazı geçirme [5], elektrolitik saflaştırma [10], fotokatalitik yanma [11] gibi çeşitli yöntemler denemişlerdir. Moon vd. [2] UV 1şınlama ve ozonlama işlemlerini birlikte uygulamışlardır. Elde edilen ${ }^{18} \mathrm{~F}$ ve ${ }^{18} \mathrm{~F}$ [FDG] verimleri, saflaştırılmış ve ilk kez kullanılmış $\left[{ }^{18} \mathrm{O}\right] \mathrm{H}_{2} \mathrm{O}$ için yaklaşık aynı olduğunu belirlemişlerdir. Asti vd. [8], 1şınlanmış $\left[{ }^{18} \mathrm{O} \mathrm{H}_{2} \mathrm{O}\right.$ içindeki organik safsızlıkları gidermede ozonlama ve damıtma yöntemlerini kullanmış ve işlem sonunda safsızlık miktarında büyük oranda düşüş olduğunu saptamışlardır. Çalışmalar, damıtma, UV ışınlama, ozonlama gibi organik safsılıkları gidermede kullanılan yöntemlerin [12, 13 ] birleştirilmiş şekilde uygulanmasının $[14,15]$ tek tek uygulanmasına göre daha etkin olduğunu göstermiştir. Son y1llarda ileri oksidasyon proseslerinden biri olan sonokimyasal oksidasyon yöntemi, atık sularda bulunan klorlu aromatik ve alifatik bileşikler, alkoller ve ilaçlar gibi organik safsızlıkların gideriminde yaygın olarak kullanılmaktadır [16, 17]. Sonokimyasal oksidasyon yöntemi, kavitasyon yolu ile oksidatif bir ortam oluşturmak için ses (sonik) ve ses ötesi (ultrasonik) dalga uygulamalarını içermektedir. Kavitasyon baloncuklarındaki su buharı ve oksijen 1sıl ayrışmaya uğrayarak $\mathrm{H}, \mathrm{OOH}, \mathrm{OH}$. radikalleri ve $\mathrm{O}$ atomlarını oluştururlar. Oluşan hidroksil radikalleri, hidrojenle tepkimeye girerek su oluşturur ya da organik bileşiğin bozunmasını sağlar $[18,19]$. Bu durum ses ötesi etkilerin, ${ }^{18} \mathrm{~F}$ [FDG] sentezi için gerekli ${ }^{18} \mathrm{~F}$ in üretiminde hedef olarak kullanılan ve işınlama sonunda bir tür atık su olan $\left[{ }^{18} \mathrm{O}\right] \mathrm{H}_{2} \mathrm{O}$ 'in saflaştırılmasında da kullanılabileceğini göstermektedir. Literatür araştırmaları sonunda 1şınlanmış $\left[{ }^{18} \mathrm{O}\right] \mathrm{H}_{2} \mathrm{O}$ saflaştırılmasında ses ötesi dalgaların tek başına ya da diğer yöntemlerle birleştirilmiş halde kullanıldı̆̆ 1 bir çalışmaya rastlanmamıştır. Bu çalışmada su içindeki organik madde gideriminde oldukça etkili olan ultrasonikasyon yöntemi de 1şınlanmış $\left[{ }^{18} \mathrm{O}\right] \mathrm{H}_{2} \mathrm{O}$ için ilk kez denenmiştir. Ozonlama, ultrasonikasyon ve damıtma yöntemlerinin arıtmadaki etkinlikleri tek tek ve birleştirilmiş yöntemler üzerinde incelenmiştir.

\section{DENEYSEL METOT (EXPERIMENTAL METHOD)}

Bu çalışmada, CTI model siklotronda $\left[{ }^{18} \mathrm{~F}\right]$ Flor üretiminde kullanılmış olan 1şınlanmış $\left[{ }^{18} \mathrm{O}\right] \mathrm{H}_{2} \mathrm{O}$ Eczacıbaşı-Monrol Nükleer Ürünler A. Ş.'den (Türkiye) temin edilmiştir. Organik bileşikler gaz kromatografi (Agillent 6890, DBWAX kolon), radyonüklidik safsızlıklar çok kanallı analizör, $\mathrm{Fe}{ }^{2+}, \mathrm{Cu}^{2+}$ and $\mathrm{Zn}^{2+}$ gibi katyonlar atomik absorpsiyon spektroskopisi (Perkin Elmer Analyst 800AAS) diğer iyonlar ise iyon kromatografi ( Dionex ICS3000) ile analiz edilmiştir. Her $\left[{ }^{18} \mathrm{~F}\right]$ Flor üretiminde $2 \mathrm{~mL}$ $\left[{ }^{18} \mathrm{O}\right] \mathrm{H}_{2} \mathrm{O}$ kullanılmaktadir. $\left[{ }^{18} \mathrm{~F}\right]$ Flor üretildikten sonra sentez cihazından alınan kullanılmış $\left[{ }^{18} \mathrm{O}\right] \mathrm{H}_{2} \mathrm{O}$ miktarı az olduğundan saflaştırma işlemi için uygulanması planlanan yöntemler hazırlanan model çözeltiler üzerinde denenmiştir. Model çözelti derişimleri kullanılmış $\left[{ }^{18} \mathrm{O}\right] \mathrm{H}_{2} \mathrm{O}$ içindeki safsızlık miktarları dikkate alınarak belirlenmiştir. Aseton (Merck) 300-42000 ppm, etanol (Merck) 40-55000 ppm ve asetonitril (Merck) 30-5500 ppm derişim aralığında hazırlanmıştır. Aynı sentez cihazından farklı üretimler sonucu alınarak karıştırılmış ışınlanmış $\left[{ }^{18} \mathrm{O}\right] \mathrm{H}_{2} \mathrm{O}$ örneklerinin analizleri ayrı ayrı yapılmış ve örnekler S1, S2, S3 olarak etiketlenmiştir (Tablo 1). Çalışılan model çözeltiler ise M1, M2 ve M3 şeklinde etiketlenmiştir.

Tablo 1. CTI model siklotronda $\left[{ }^{18} \mathrm{~F}\right]$ Flor üretiminde kullanılmış olan 1şınlanmış $\left[{ }^{18} \mathrm{O}\right] \mathrm{H}_{2} \mathrm{O}$ örnekleri

(Iradiated $\left.{ }^{18} \mathrm{O}\right] \mathrm{H}_{2} \mathrm{O}$ used $\left[{ }^{18} \mathrm{~F}\right]$ fluoride production in CTI model cyclotron)

\begin{tabular}{llll}
\hline $\begin{array}{l}\text { Örnek } \\
\text { No }\end{array}$ & $\begin{array}{l}\text { Aseton } \\
(\mathrm{ppm})\end{array}$ & Etanol(ppm) & Asetonitril $(\mathrm{ppm})$ \\
\hline S1 & - & 300 & 5500 \\
S2 & 35000 & 50000 & 5000 \\
S3 & 400 & - & 30 \\
\hline
\end{tabular}

Organik safsızlıkları gidermek için ozonlama, ultrasonikasyon, damitma yöntemleri ve ozonlamadamıtma, utrasonikasyon+damıtma ardışık işlemleri, ozonlama+ ultrasonikasyon eş anlı işlemleri önce model bileşiklere sonra etiketlenmiş örneklere uygulanmıştır. Ozonlama işlemi için kapasitesi $400 \mathrm{mg} / \mathrm{h}$ olan OPAL OG 
400 marka ozon jeneratörü, ultrasonikasyon işlemi için 20 $\mathrm{kHz}$ frekansta ve $300 \mathrm{~W}$ gücünde SONICS VIBRA CELL marka bir cihaz ve damıtma işlemi için laboratuvarda kurulmuş basit bir düzenek kullanılmıştır. Ayrıca $\left[{ }^{18} \mathrm{~F}\right] \mathrm{Flor}$ üretimi için SIEMENS CTI marka siklotron, $\left[{ }^{18} \mathrm{~F}\right] \mathrm{FDG}$ üretimi için ise IBA - Synthera marka sentez cihazı kullanılmıştır.

\section{SONUÇLAR VE TARTIŞMALAR (RESULTS AND DISCUSSIONS)}

Işınlanmış $\left[{ }^{18} \mathrm{O}\right] \mathrm{H}_{2} \mathrm{O}$ içindeki iyonik, radyonüklidik ve organik safsızlıkların analizi yapılarak miktarları belirlenmiş ve saflaştırma işlemleri uygulanmıştır. Yapılan analizler sonucu 1şınlanmış $\left[{ }^{18} \mathrm{O}\right] \mathrm{H}_{2} \mathrm{O}$ örnekler içindeki iyonik safsızlık miktarlarının siklotronda ışınlamaya ya da üretim verimine etki etmeyecek ölçüde olduğu belirlenmiştir (Tablo 2). Literatürde, eser miktardaki iyonik safsızlıkları içeren 1şınlanmış $\left[{ }^{18} \mathrm{O}\right] \mathrm{H}_{2} \mathrm{O}$ ve taze $\left[{ }^{18} \mathrm{O}\right] \mathrm{H}_{2} \mathrm{O}$ ile elde edilen üretim verimleri birbirine çok yakın olduğu bulunmuştur $[2,4]$. Analizlenen $\left[{ }^{18} \mathrm{O}\right] \mathrm{H}_{2} \mathrm{O}$ örnekleri içinde radyolüklidik safsızlığa rastlanmamıştır. Işınlanmış $\left[{ }^{18} \mathrm{O}\right] \mathrm{H}_{2} \mathrm{O}$ daki organik safsızlık içeriğinin 30-5500 ppm asetonitril, 400-35000 ppm aseton ve 300-50000 ppm etanol olduğu belirlenmiştir (Tablo 1). Farklı sentez cihazlarından elde edilen örnekler kullanılan kimyasal maddelere bağlı olarak farklı derişimde kirletici içermekle birlikte aynı sentez cihazından farklı üretimler sonunda alınan örneklerin de organik safsızlık içerikleri farklı olabilmektedir (Tablo 1). Öncelikle örneklerde belirlenen derişim oranları dikkate alınarak hazırlanan model çözeltiler ile saflaştırma işlemleri gerçekleştirilmiştir. Ozonlama işleminin organik madde giderimine etkisini görmek için ilk olarak organik safsızlıkları tek tek içeren model çözeltiler hazırlanmış ve ozonlama işlemi uygulanmıştır. Bu işlemde model çözeltiler içindeki organik maddeler tamamen giderilinceye kadar ozonlanmıştır. Çalışmalar farklı başlangıç derişimlerindeki çözeltiler için yapılarak başlangıç derişimi ve ozonlama süresinin organik kirliliklerin giderimine etkisi araştırılmıştır. Sadece aseton, etanol ya da asetonitril içeren farklı başlangıç derişimindeki model çözeltilerin ozonlama işlemi sonuçları Şekil 1a, Şekil $1 b$ ve Şekil 1c'de verilmiştir. Sonuçlar incelendiğinde aseton için başlangıç derişiminin organik madde giderimini büyük ölçüde etkilemediği görülmüştür. 4 saat ozonlama işlemi ile 400 - 35000 ppm derişiminde aseton içeren çözelti içindeki asetonun tamamı giderilebilmektedir. Etanol giderimi incelendiğinde etanolün, aseton ve asetonitrile göre daha yavaş giderildiği gözlemlenmiştir. Bu durum alkollerin suda çözünmüş halde bulunmalarına bağlı olarak ozon gibi elektrofillere ulaşmasının zor olması ile açıklanabilir. Benzer bulgular süreli yayınlarda rastlanmaktadır [20]. 4 saat ozonlama işlemi sonunda etanolün \%30-40 civarında giderildiği saptanmıştır. Farklı başlangıç derişimlerinde hazırlanan asetonitril çözeltilerinin ozonlama işlemi sonuçları incelendiğinde ise asetonitril gideriminin asetona göre daha yavaş olduğu gözlenmiştir. $50 \mathrm{dk}$ sonunda asetonitril giderimi $\% 50$ civarında iken, aseton giderimi \%60-70'e kadar çıkmıştır. Başlangıç derişimine bağlı olarak 4 saat işlem sonundaki giderim oranı $\% 90$ ile $\% 100$ arasında değişmektedir.

Ultrasonikasyon yöntemi 1şınlanmış $\quad\left[{ }^{18} \mathrm{O}\right] \mathrm{H}_{2} \mathrm{O}$ 'in saflaştırılması için ilk kez denenmiştir. Ultrasonikasyon işlemi için de ozonlama işleminde olduğu gibi önce model çözeltilerle çalışılmış ve uygun koşullar belirlendikten sonra bu koşullarda yöntem işınlanmış $\left[{ }^{18} \mathrm{O}\right] \mathrm{H}_{2} \mathrm{O}$ örneklerine uygulanmıştır. İlk olarak organik safsızlıkları tek tek içeren model çözeltiler hazırlanmış ve bir saat boyunca ultrasonikasyon işlemi uygulanmıştır. Yapılan ilk çalışmada sıcaklık artışı çok olduğu için bütün deneyler subuz banyosunda, sicaklik $20-25^{\circ} \mathrm{C}^{\prime}$ da tutularak gerçekleştirilmiştir. Sicaklık kontrolü zor olduğu için ultrasonikasyon işlemi örneklere bir saat uygulanmış bulgular Şekil 2a, Şekil 2b ve Şekil 2c'de verilmiştir. 1 saat ultrasonikasyon ugulanmış model bileşiklerde başlangıç derişimine bağlı olarak aseton gideriminin \%30-70, etanol gideriminin \%4-15 ve asetonitril gideriminin ise \%20-45 arasında olduğu belirlenmiştir. Başlangıç derişimi ile \%

Tablo 2. Farklı sentezlerden alınan ışınlanmış $\left[{ }^{18} \mathrm{O}\right] \mathrm{H}_{2} \mathrm{O}$ örneklerinin iyon analizi (Ion analysis of $\left[{ }^{18} \mathrm{O}\right] \mathrm{H}_{2} \mathrm{O}$ samples obtained from different synthesis)

\begin{tabular}{lllll}
\hline Test & $\mathrm{S} 1$ & $\mathrm{~S} 2$ & $\mathrm{~S} 3$ & $\begin{array}{l}\text { Spesifikasyon } \\
\mathrm{mg} / \mathrm{mL}\end{array}$ \\
\hline $\mathrm{Ca}^{2+}$ & 0,6144 & 0,0021 & 0,2110 & $<1$ \\
$\mathrm{Mg}^{2+}$ & 0,0374 & 0,0058 & 0,2208 & $<1$ \\
$\mathrm{Na}^{+}$ & 0,3011 & 0,0686 & 2,1672 & $<2$ \\
$\mathrm{~K}^{+}$ & 4,2481 & 1,5046 & 0,2827 & $<1$ \\
$\mathrm{Fe}^{2+}$ & 0,0769 & 0,0856 & 0,0397 & $<0,1$ \\
$\mathrm{NH}_{4}^{+}$ & 0,6654 & 0,1293 & 0,2501 & $<1$ \\
$\mathrm{Zn}^{2+}$ & 0,0305 & 0,1937 & 0,5003 & $<1$ \\
$\mathrm{Cu}^{2+}$ & 0,0389 & 0,0005 & 0,0345 & $<1$ \\
$\mathrm{~F}^{-}$ & 0,5722 & 0,9158 & 0,0627 & $<1$ \\
$\mathrm{Cl}^{-}$ & 2,5623 & 0,6402 & 0,3085 & $<1$ \\
$\mathrm{Br}^{-}$ & 0,1287 & 0,1775 & 0,0977 & $<1$ \\
$\mathrm{NO}_{3}^{-}$ & 0,4462 & 0,1284 & 0,3368 & $<1$ \\
$\mathrm{PO}_{4}{ }^{3-}$ & 0,8975 & 0,0021 & 0,0024 & $<1$ \\
$\mathrm{SO}_{4}^{2-}$ & 0,1625 & 0,1754 & 0,1391 & $<1$ \\
\hline
\end{tabular}




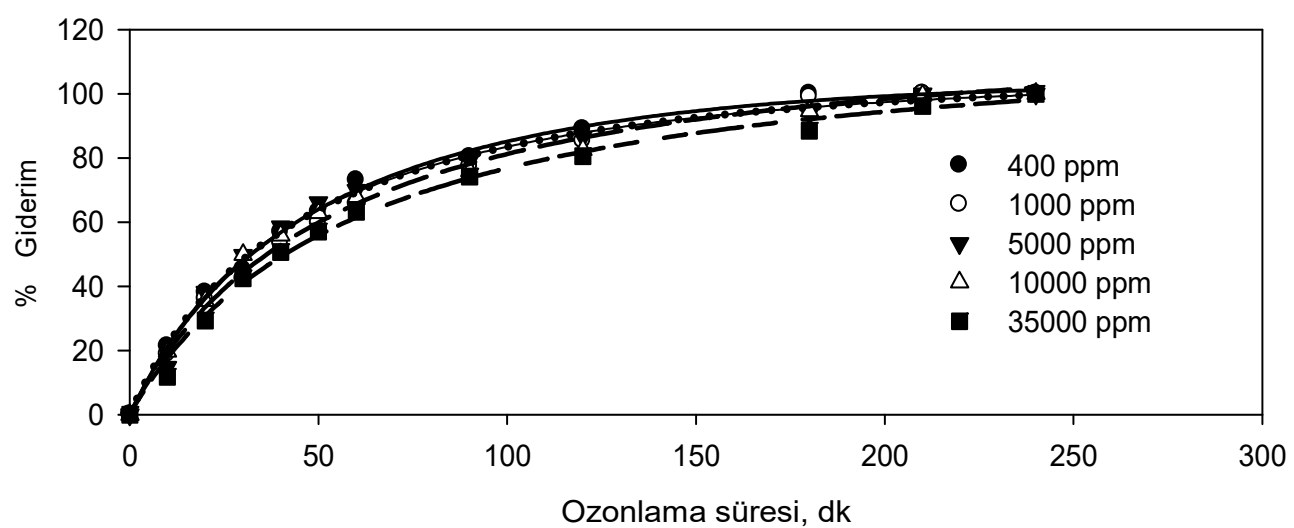

(a)

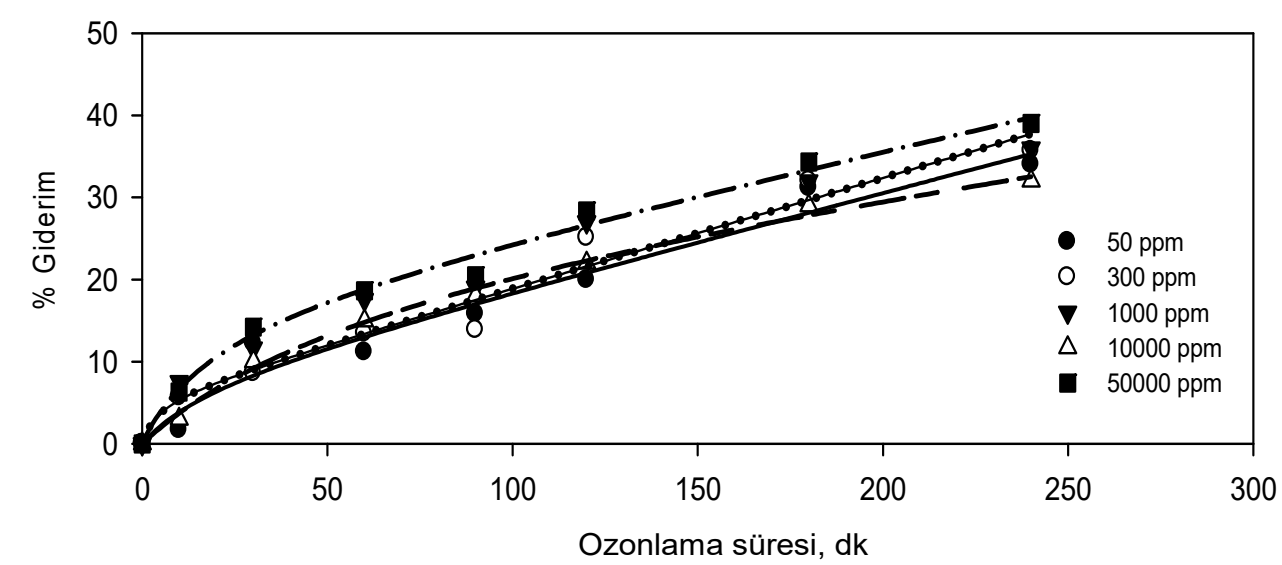

(b)

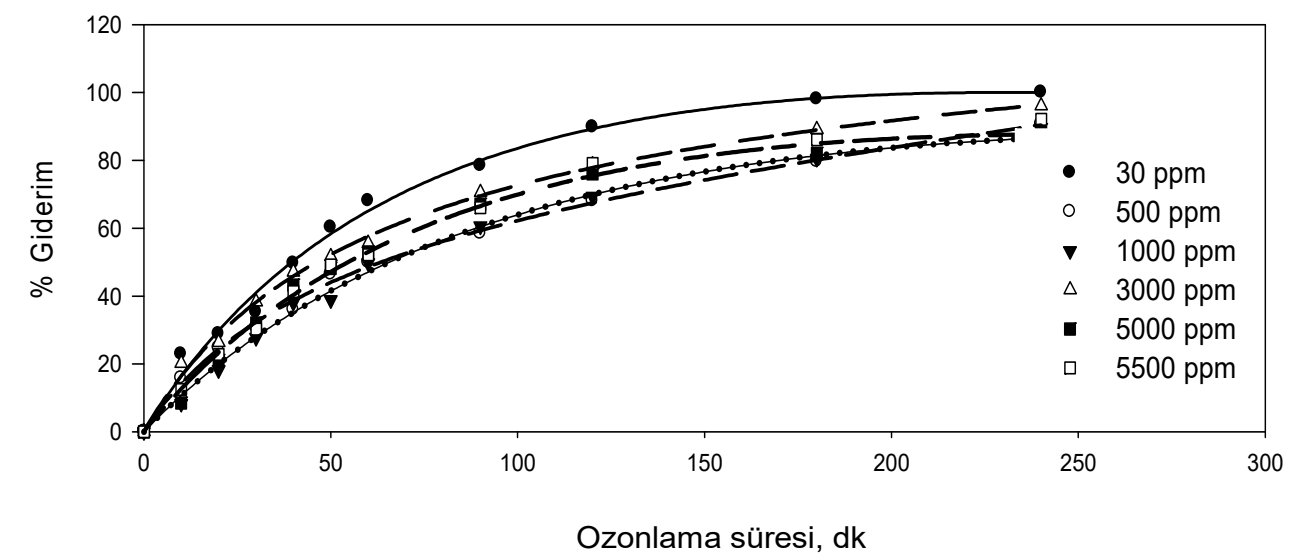

(c)

Şekil 1. Ozonlama süresi ve başlangıç derişiminin organik safsızlık giderimine etkisi a)Aseton b) Etanol c) Asetonitril (The effect of ozonoloysis time and initial concentration on removal of organic impurities a) Acetone b) ethanol c) Acetonitrile)

giderim değerlerinde anlamlı bir değişim olmamakla birlikte etanol ve asetonitril için yüksek derişimlerde de yüksek \%giderim elde edilmiştir. Organik safsızlıkların tek tek ozonlanması incelendikten sonra üç organik safsızlığı da içeren model çözeltiler hazırlanmış ve ozonlama, ultrasonikasyon ve damıtma işlemleri uygulanmış, sonuçlar Tablo 3'de verilmiştir. Organik maddeleri tek tek içeren 596 model çözeltilerde organik madde giderimi ile üç organik safsızlığı da içeren model çözelti içindeki ozonlama ile giderim oranları karşılaştırıldığında aseton ve asetonitril için \% giderim değerlerinde bir fark olmadığı söylenebilir; ancak etanol ve asetonitrili birlikte içeren çözeltide, derişimi düşük olmasına rağmen etanol gideriminin asetonitril gideriminden daha düşük olduğu gözlenmiştir. 


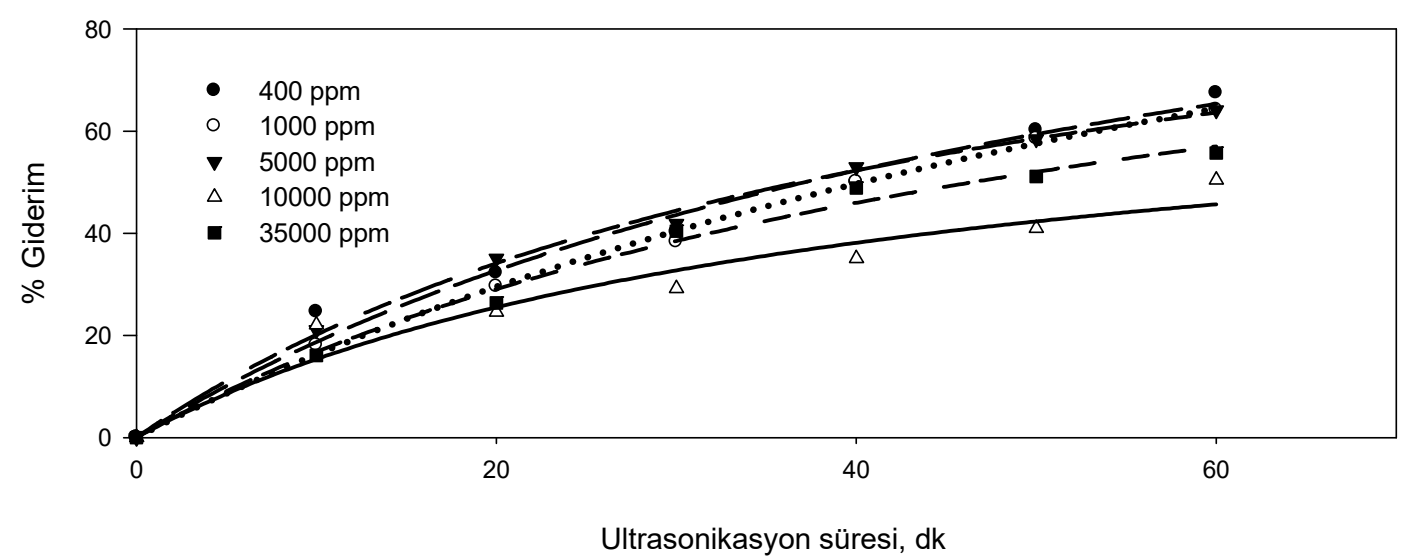

(a)

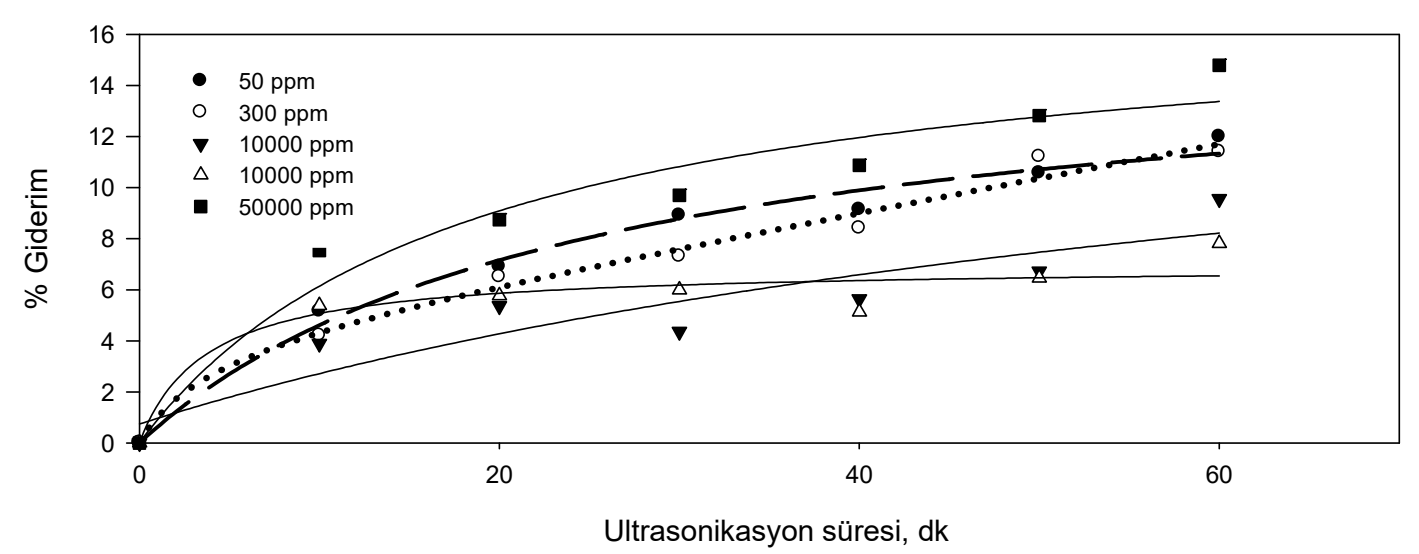

(b)

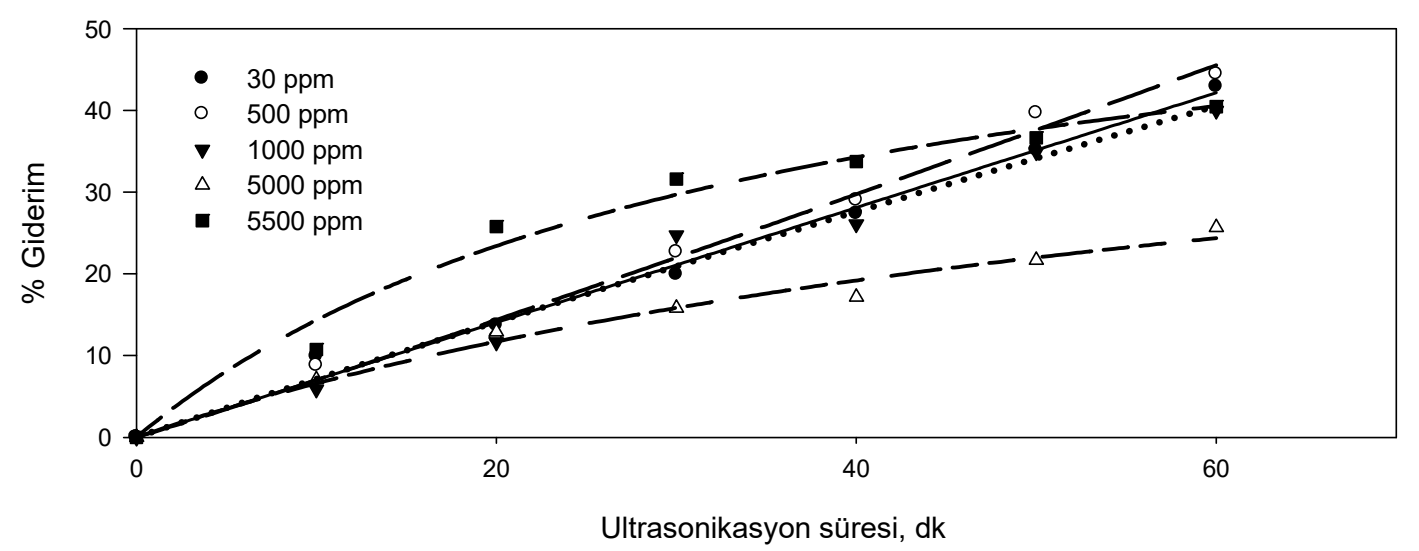

(c)

Şekil 2. Ultrasonikasyon süresi ve başlangıç derişiminin organik safsızlık giderimine etkisi a)Aseton b) Etanol c)

Asetonitril (The effect of ultrasonication time and initial concentration on removal of organic impurities a)Acetone b) Ethanol c)Acetonitrile)

Üç safsızlığ da içeren model çözeltiler içindeki asetonun ultrasonikasyon yöntemi ile giderimi, sadece aseton içeren model çözeltilerle karşılaştırıldığında, daha düşük olduğu gözlenmiştir. 1000 ppm aseton içeren çözeltideki aseton giderimi \%65 iken (Şekil 2a), üç safsızlığı da içeren çözeltideki (Tablo 3) aseton giderimi \%55'dir. Ultrasonikasyon yönteminde ortamda etanol ve asetonitrilin varlığ 1 aseton giderimini olumsuz etkilemektedir. 5500 ppm derişiminde asetonitril içeren karışım halindeki çözeltide (Tablo 3) giderim \%35 civarındadır. Bu değer sadece asetonitril içeren çözeltide (Şekil 2c) elde edilen sonuç ile aynıdır; ancak bu durum ikili karışımlar için değişmektedir. Sadece 30 ppm derişiminde asetonitril içeren (Şekil 2c) çözeltide giderim \%45 iken etanol ve asetonitril içeren model çözeltide (Tablo 3) asetonitril giderimi \%25 civarında kalmıştır. Aseton ve asetonitril içeren model 
çözeltideki (Tablo 3) asetonitril giderimi incelendiğinde ise $\% 25$ civarında olduğu görülmüştür. Aynı derişimde sadece asetonitril içeren çözeltideki (Şekil 2c) giderim ise \%45'dir. Model çözelti karışımlarından organik safsızlıkların giderimi damıtma yöntemi ile de gerçekleştirilmiş ve sonuçlar Tablo 3'de verilmiştir. Damitma ile elde edilen giderim oranları ozonlama ve ultrasonikasyon yöntemi ile elde edilenlere göre daha yüksek bulunmuştur. Ancak toplam madde kaybı damıtma işlemi için bir dezavantajdır. Deneysel sonuçlar saflaştırma işleminden sonra toplam örneğin yaklaşık \%70 inin $\mathrm{F}^{18}$ sentezinde kullanım için uygun olduğunu ortaya koymuştur. Model çözeltilerle farklı derişimlerde ve ikili - üçlü kirletici içeren örneklerde giderim için gerçekleştirilen ozonlama, ultrasonikasyon ve damıtma ön deneylerinden sonra, 1şınlanmış $\left[{ }^{18} \mathrm{O}\right] \mathrm{H}_{2} \mathrm{O}$ içindeki safsızlıkların giderimi için ozonlama ve ultrasonikasyon işlemleri uygulanmış sonuçlar Şekil 3 ve Şekil 4'de verilmiştir. Elde edilen sonuçlar model çözeltiler ile elde edilenler ile benzer bulunmuştur. Sonuçlar ozonlama işleminin organik madde gideriminde oldukça etkili bir yöntem olmasına rağmen $\mathrm{H}_{2} \mathrm{O}$ oluşumundan dolayı uzun ozonlama sürelerinin organik maddelerin giderimi için uygun olmadığını göstermiştir. Ozonlama işlemi sonucu organik maddelerin oksidasyonu ile $\mathrm{CO}_{2}$ ve $\mathrm{H}_{2} \mathrm{O}$ gibi ürünlerin oluştuğu bilinmektedir [8].

Oluşan $\mathrm{H}_{2} \mathrm{O}, \quad\left[{ }^{18} \mathrm{O}^{\mathrm{H}} \mathrm{H}_{2} \mathrm{O}\right.$ içindeki $\%$ O-18 miktarını azaltacağı için, en uygun ozonlama süresi belirlenmelidir. Bunu belirlemek için Fawdry'nin [3] çalışmasında yararlandığ gravimetrik analiz yöntemi uygulanmıştır. Üç farklı 1şınlanmış $\left[{ }^{18} \mathrm{O}\right] \mathrm{H}_{2} \mathrm{O}$ örneği 4 saat boyunca ozonlanmış ve belirli sürelerde örnek alınarak organik safsızlıklar için gaz kromatografi analizleri yapılmş ve \% O-18 miktarları gravimetrik olarak belirlenmiştir (Tablo 4). Sonuçlar incelendiğinde \% O-18 miktarının azalmaması için en uygun ozonlama süresinin 10 dakika olduğuna karar verilmiştir, ancak 10 dakika ozonlama işlemi ile organik maddelerin tümü giderilememiştir (Şekil 3). Bu nedenle ozonlama işleminin diğer yöntemlerle birleştirilerek uygulanması gerektiği düşünülmüştür. Ozonlama işlemine benzer olarak ultrasonikasyon işleminde de oluşan hidroksil radikallerinin hidrojenle birleşmesi ile su oluşur. Oluşan su \% O-18 miktarını azaltacağı için ultrasonikasyon işlemi sonucu 1şınlanmış $\left[{ }^{18} \mathrm{O}\right] \mathrm{H}_{2} \mathrm{O}$ içindeki \% $\mathrm{O}-18$ miktarları belirlenmiştir [3]. Üç farklı 1şınlanmış $\left[{ }^{18} \mathrm{O}\right] \mathrm{H}_{2} \mathrm{O}$ örneğine bir saat boyunca ultrasonikasyon işlemi uygulanmış ve belirli sürelerde örnek alınarak \% O-18 miktarı gravimetrik olarak belirlenmiştir (Tablo 4). Örneklerin ultrasonikasyon ile organik madde giderim sonuçları Şekil 4'de verilmiştir. Şekil 4 ve Tablo 4 incelendiğinde ultrasonikasyon süresinin artması ile giderilen organik madde miktarının arttığ \% O- 18 miktarının azaldığı görülmektedir. Siklotronda saflaştırılmış $\left[{ }^{18} \mathrm{O}\right] \mathrm{H}_{2} \mathrm{O}$ nin hedef olarak kullanılabilirliği kimyasal saflığı yanında \% O-18 zenginliği de göz önünde bulundurularak değerlendirilir. Bu yüzden ultrasonikasyon süresi \% O-18 miktarını etkileyen önemli bir parametredir. Organik madde miktarı az olduğunda \% O-18 miktarında büyük bir değişiklik olmadan bir saat ultrasonikasyon işlemi ile organik safsızlıklar giderilebilmektedir; ancak safsızlıkların tümü giderilemediği için ultrasonikasyon işlemine ek olarak başka yöntemlerin kullanılması gerekmektedir. Ozonlama, ultrasonikasyon ve damitma işlemleri organik maddelerin gideriminde etkin yöntemler olmasına rağmen, yöntemlerin tek başına uygulanması yukarıda siralanan nedenlerden dolay $\left[{ }^{18} \mathrm{O}_{\mathrm{H}_{2} \mathrm{O}}\right.$ in saflaştırılmasında uygun değildir. $\mathrm{Bu}$ nedenle ozonlama+damıtma, ultrasonikasyon+damıtma ardişık işlemleri ve ozonlama+ultrasonikasyon eşanlı yöntemlerinin model çözeltilerdeki organik safsızlıkları gidermedeki etkinlikleri incelenmiş ve sonuçlar Tablo 5 'de verilmiştir. Ozonlama işleminde su miktarındaki artış nedeni ile ozonlama süresi 10 dakika olarak alındığını belirtmiştik. 10 dakika ozonlama işlemi ile de organik maddelerin tamamı giderilemediği için ozonlama işleminden sonra damıtma işlemi uygulanmış ve organik madde giderimi incelenmiştir. Yapılan ozonlama işlemi sonuçlarında organik madde gideriminin başlangıç derişimi ile doğrudan ilgili olmadığı belirlenmişti. Bu yüzden $10 \mathrm{dk}$ ozonlama işlemi ile elde edilen \% giderim değerleri üç örnekte de birbirine yakın bulunmuştur. $10 \mathrm{dk}$ ozonlama işleminden sonra yapılan damıtma işlemi ile de organik safsızlıklar büyük ölçüde giderilmiştir. Ozonlama-damıtma ardışık işlemi tek başına damıtma işlemi ile karşılaştırıldığında üç organik safsızlığı da içeren örnekte toplam \% geri kazanım oranı ozonlama-damıtma ardışık işleminde daha yüksek olmuştur (Tablo 6).

Tablo 3. Ozonlama, ultrasonikasyon ve damıtma işlemi uygulanmış ikili ya da üçlü kirletici içeren model çözeltilerde \% giderim

(\% removal in model solutions containing dual or ternary contaminants applied ozonolysis, ultrasonication and distillation)

\begin{tabular}{lllll}
\hline $\begin{array}{l}\text { Örnek } \\
\text { No }\end{array}$ & $\begin{array}{l}\text { Organik kirletici } \\
\text { (ppm) }\end{array}$ & $\begin{array}{l}\text { \% Giderim Ozonlama } \\
\text { işleminden } \\
\text { sonra }(240 \mathrm{dk})\end{array}$ & $\begin{array}{l}\text { \% Giderim } \\
\text { Ultrasonikasyon } \\
\text { işleminden sonra (60 dk) }\end{array}$ & $\begin{array}{l}\text { \% Giderim } \\
\text { damitma } \\
\text { işleminden sonra }\end{array}$ \\
\hline M1 & Etanol (300) & 20 & 7 & 74 \\
& Asetonitril (5500) & 100 & 25 & 100 \\
M2 & Aseton(900) & 100 & 55 & 94 \\
& Etanol (50) & 30 & 20 & 56 \\
& Asetonitril (5500) & 100 & 35 & 89 \\
M3 & Aseton (400) & 100 & 32 & 100 \\
& Asetonitril (30) & 100 & 24 & 100 \\
\hline
\end{tabular}




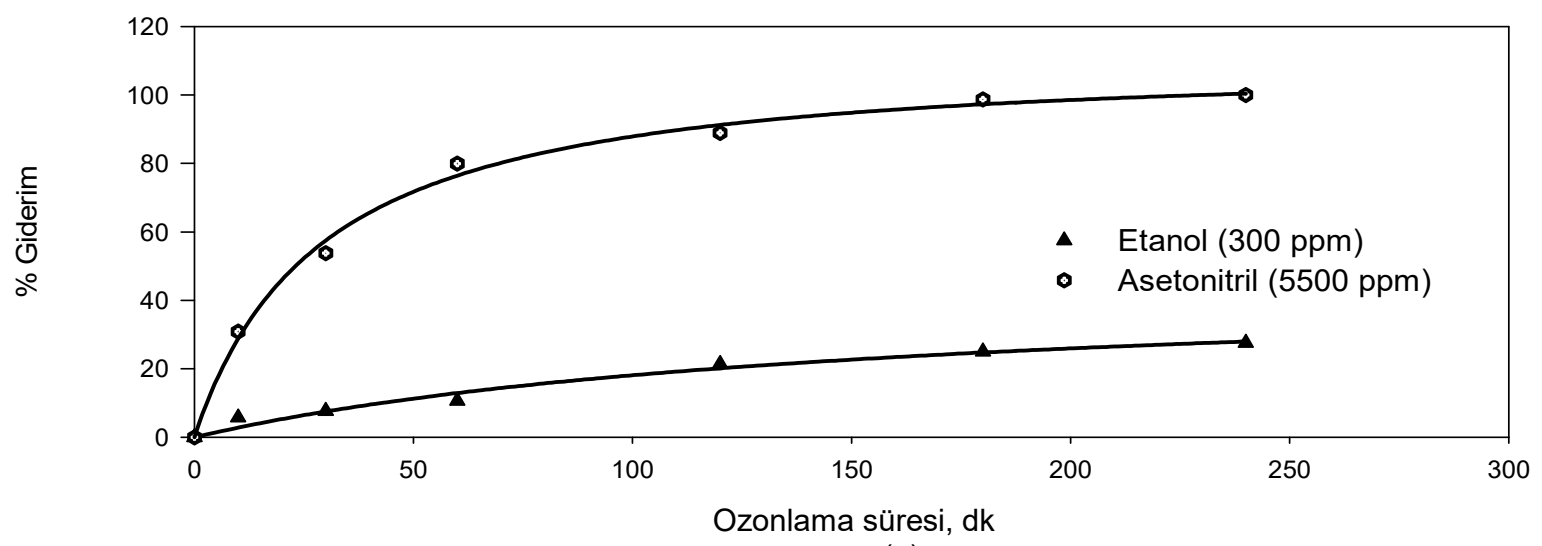

(a)

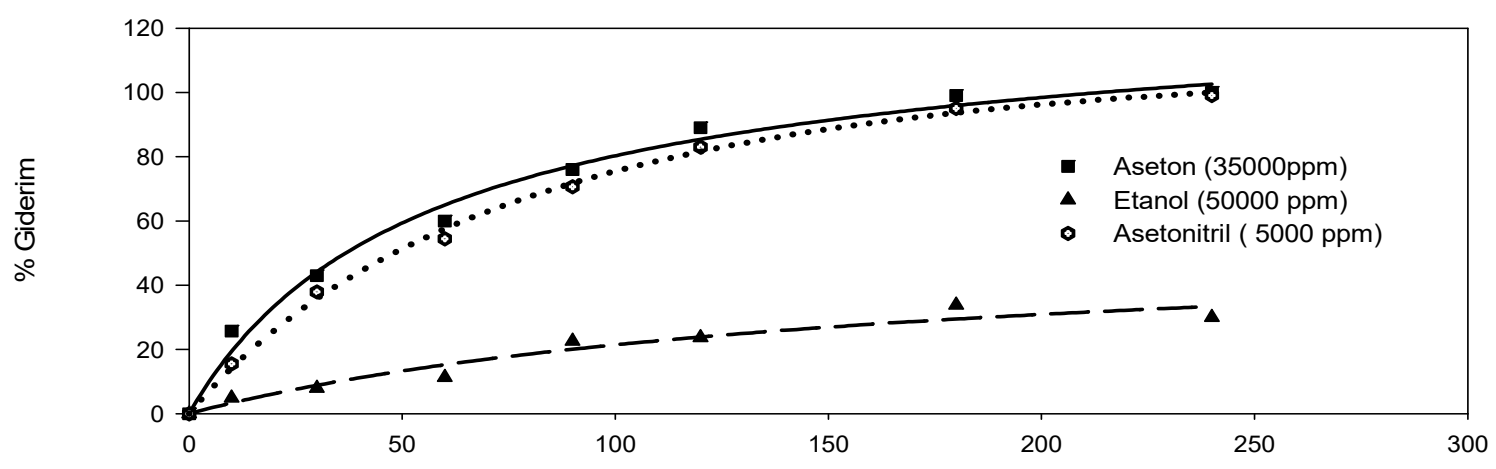

Ozonlama süresi, $\mathrm{dk}$

(b)

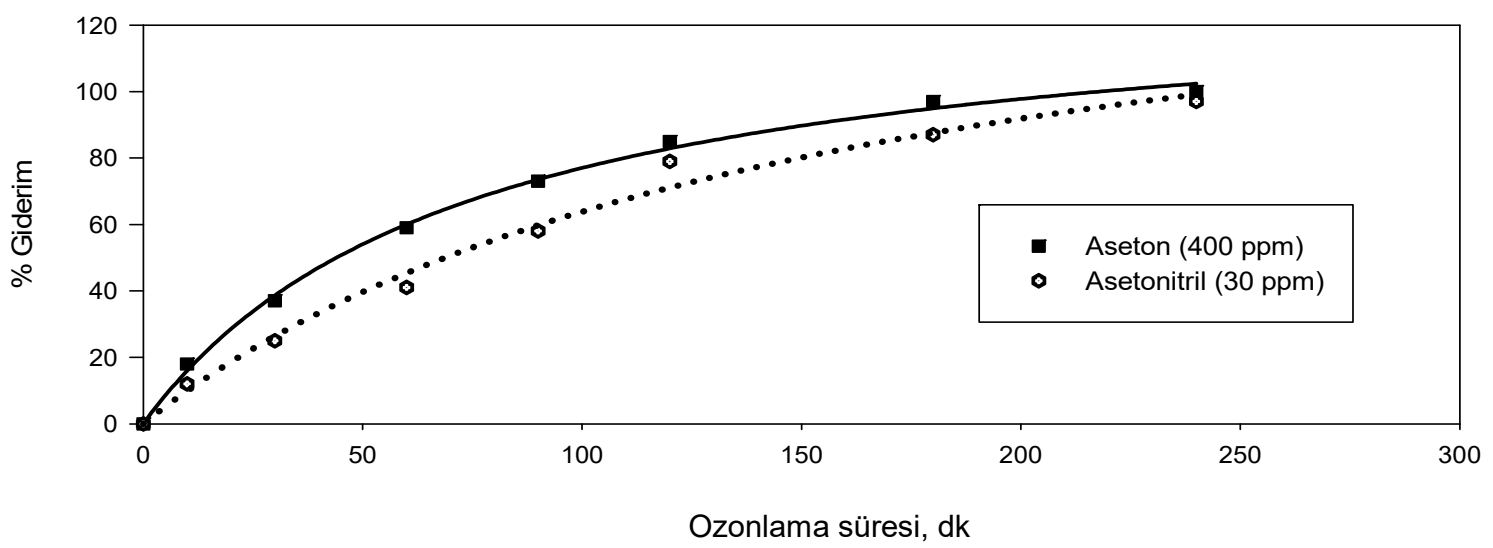

(c)

Şekil 3. Işınlanmış $\left[{ }^{18} \mathrm{O}\right] \mathrm{H}_{2} \mathrm{O}$ örneklerine ozonlama işlemi uygulaması a) $\mathrm{S} 1$ b) $\mathrm{S} 2$ c) $\mathrm{S} 3$ (Application of ozonolysis process on irradiated $\left[{ }^{18} \mathrm{O}^{\mathrm{H}} \mathrm{H}_{2} \mathrm{O}\right.$ samples a) $\mathrm{S} 1$ b) $\mathrm{S} 2$ c) $\mathrm{S} 3$ )

Üç safsızlığ da içeren $150 \mathrm{~mL}$ örneğin tek başına damıtma işlemi ile $\% 73$ 'ü $(110 \mathrm{~mL})$ aseton miktarı $4 \mathrm{ppm}$, etanol miktarı $7 \mathrm{ppm}$ ve asetonitril miktarı $110 \mathrm{ppm}$ değerine düşürülmüştür. Aynı miktarda safsızlık içeren örneğe $10 \mathrm{dk}$ ozon ardından damıtma işlemi uygulandığında ise $150 \mathrm{~mL}$ örneğin \% 87'si (130 mL) geri kazanılmıştır. Bu örnek içindeki aseton miktarı $50 \mathrm{ppm}$, etanol miktarı $10 \mathrm{ppm}$ ve asetonitril miktarı $320 \mathrm{ppm}$ dir (Tablo 6). Etanol ve asetonitril (M1) ya da aseton ve asetonitril (M3) içeren örneklerin geri dönüşümleri incelendiğinde ise tek başına damıtma işlemi ve $10 \mathrm{dk}$ ozonlama ardından damıtma işlemleri arasında belirgin bir fark gözlenmemiştir. Etanol ve asetonitril içeren örneğe tek başına damıtma işlemi uygulandığında örneğin \%87'si $(130 \mathrm{~mL})$ etanol miktarı $300 \mathrm{ppm}$ değerinde, asetonitril ise tamamen giderilmiş şekilde geri kazanılmıştır. Aynı örneğe $10 \mathrm{dk}$ ozon ardından 


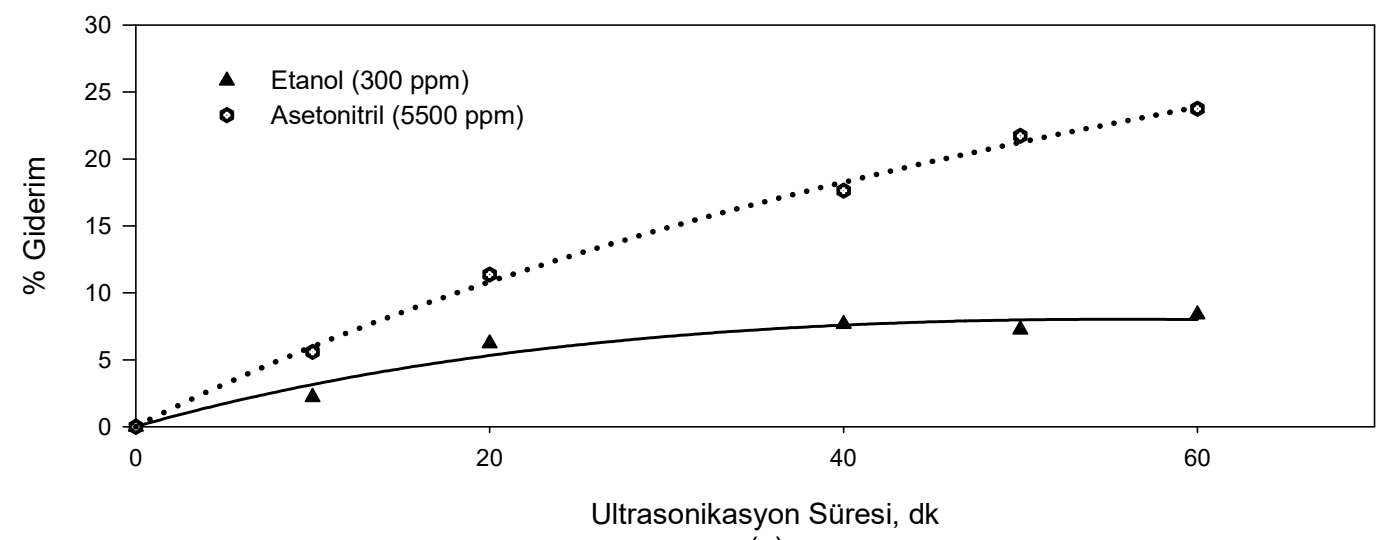

(a)

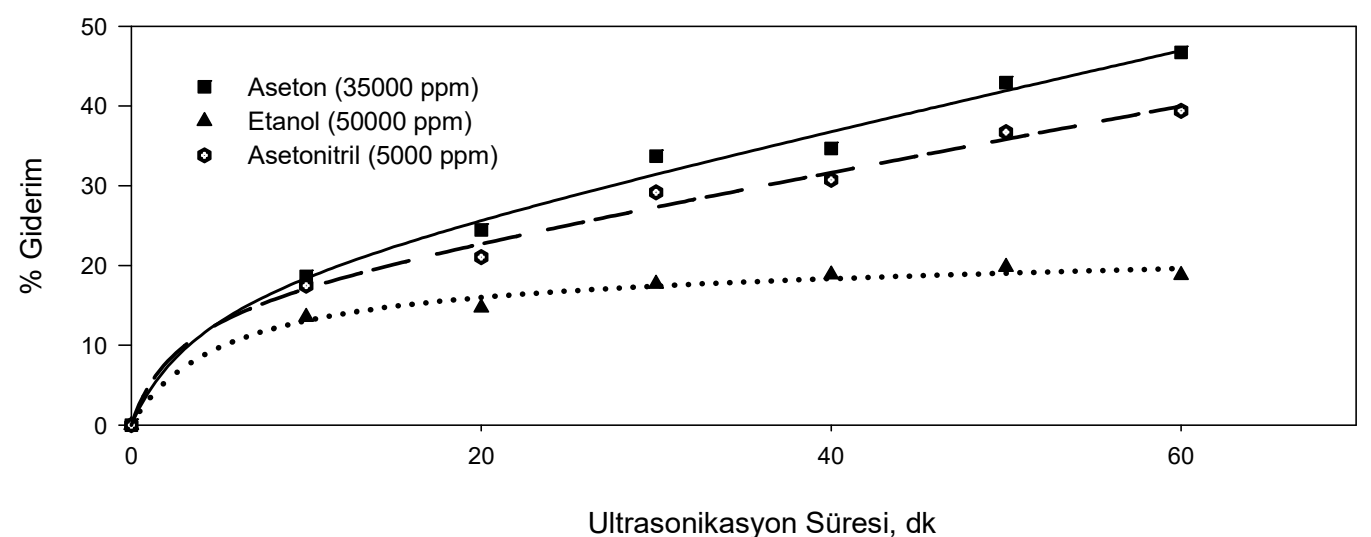

(b)

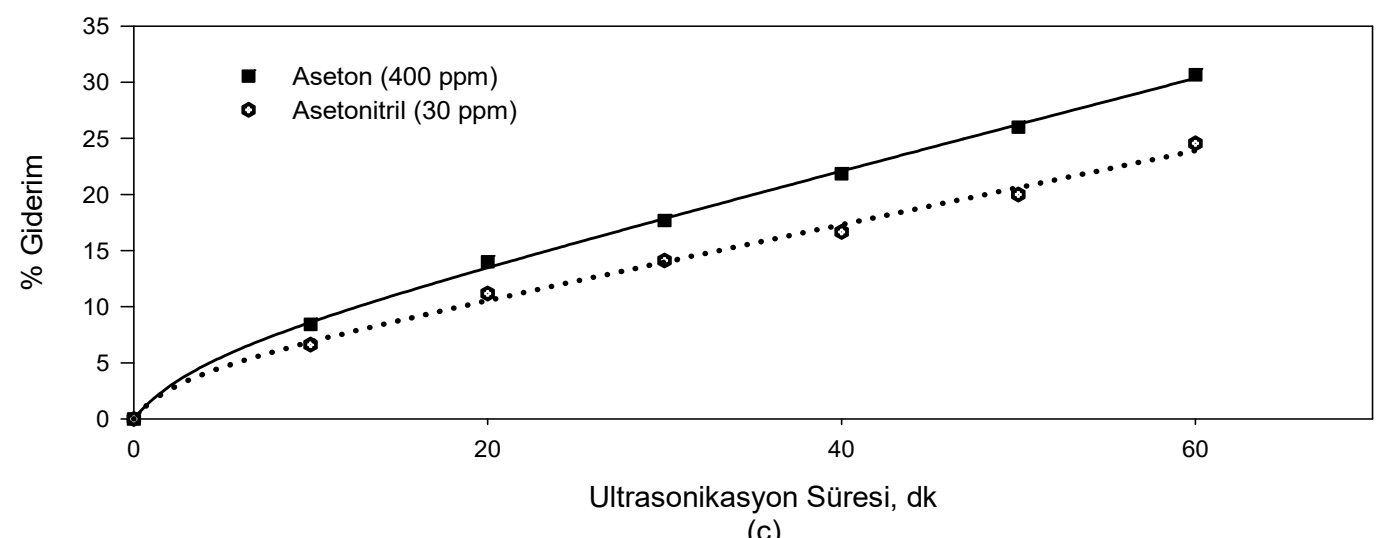

(c)

Şekil 4. Işınlanmıș $\left[{ }^{18} \mathrm{O}\right] \mathrm{H}_{2} \mathrm{O}$ örneklerine ultrasonikasyon işlemi uygulaması a)S1, b) S2, c) S3

(Application of ultrasonication process on 1 rradiated $\left[{ }^{18} \mathrm{O} \mathrm{H}_{2} \mathrm{O}\right.$ samples a)S1, b)S2, c)S3)

damıtma işlemi uygulandığında ise geri dönüşüm oranı damıtma işlemindeki gibi \%87 olarak belirlenmiştir. Bu örnek içindeki etanol miktarı 260 ppm, asetonitril miktarı ise 4 ppm dir. Aseton ve asetonitril içeren örneğe uygulanan tek başına damıtma işlemi ile $10 \mathrm{dk}$ ozonlama ardından damıtma işlemi sonuçları karşılaştırıldığında ise iki işlem sonucunda elde edilen saflaştırılmış örnek miktarları arasında fark olmadığı gözlenmiştir. İki uygulamada da \% geri dönüşüm \%93'dür ve safsızlıklar 600 tamamen giderilmiştir. Sonuç olarak safsızlık miktarları yüksek olduğunda ozonlama işlemi ardından damıtma işlemi, tek başına damıtma işlemine göre geri kazanım oranı açısından daha uygun olduğu belirlenmiștir. Safsızlık miktarları daha az olduğunda ise iki uygulama arasında fark olmadığı gözlemlenmiştir. Bu nedenle safsızlık miktarı az olduğunda enerji ve zaman kaybına neden olmamak için tek başına damıtma işlemi uygulamak daha avantajlı olduğu düşünülmektedir. 
Tablo 4. Işınlanmış örneklerin ozonlama, ultrasonikasyon ve ozonlama+ ultrasonikasyon işlemlerinden sonra gravimetrik olarak belirlenmiş \% O-18 değerleri

( $\mathrm{O}-18 \%$ data of urradiated samples determined as gravimetricaly after ozonolysis, ultrasonication and ozonolysis + ultrasonication process)

\begin{tabular}{llllllll}
\hline \multicolumn{7}{c}{$\%\left[{ }^{18} \mathrm{O}\right]$} \\
\hline Örnek No & Işınlanmış $\left[{ }^{18} \mathrm{O}\right] \mathrm{H}_{2} \mathrm{O}$ & \multicolumn{2}{l}{ Ozonlama Süresi (dk) } \\
& & 10 & 30 & 60 & 120 & 180 & 240 \\
$\mathrm{~S} 1$ & 91,21 & 90,15 & 87,18 & 88,76 & 89,98 & 87,18 & 81,21 \\
$\mathrm{~S} 2$ & 92,30 & 90,37 & 90,42 & 89,32 & 86,69 & 84,93 & 78,79 \\
$\mathrm{~S} 3$ & 89,71 & 86,62 & 86,37 & 86,45 & 84,52 & 85,40 & 79,62
\end{tabular}

\begin{tabular}{llllllll}
\multicolumn{7}{c}{ Ultrasonikasyon Süresi (dk) } \\
& & 10 & 20 & 30 & 40 & 50 & 60 \\
S1 & 91,21 & 88,86 & 88,92 & 90,69 & 89,99 & 89,63 & 89,52 \\
S2 & 92,30 & 78,8 & 75,32 & 74,98 & 73,27 & 73,51 & 73,04 \\
S3 & 89,71 & 89,28 & 88,57 & 88,29 & 86,45 & 85,98 & 85,28
\end{tabular}

Ozonlama-ultrasonikasyon eşanlı işlemi süresi (dk)

\begin{tabular}{llllllll} 
S1 & 91,21 & 90,68 & 90,15 & 89,97 & 89,61 & 89,08 & 87,31 \\
S2 & 92,30 & 80,95 & 80,42 & 78,11 & 77,06 & 76,53 & 76,00 \\
S3 & 89,71 & 90,09 & 89,87 & 89,13 & 88,65 & 88,11 & 87,97 \\
\hline
\end{tabular}

Tablo 5. Birleştirilmiş yöntemler için organik safsızlıkların \% giderim (Removal \% of organic impurities for combined methods)

\begin{tabular}{|c|c|c|c|c|}
\hline $\begin{array}{l}\text { Örnek } \\
\text { No }\end{array}$ & $\begin{array}{l}\text { Organik } \\
\text { safsızlık }\end{array}$ & $\begin{array}{l}\text { \%Giderim } \\
\text { ozonlama+damıtma }\end{array}$ & $\begin{array}{l}\text { \%Giderim } \\
\text { ultrasonikasyon+damıtma }\end{array}$ & $\begin{array}{l}\text { \%Giderim } \\
\text { ozonlama+ultrasonikasyon }\end{array}$ \\
\hline \multirow[t]{2}{*}{ M1 } & etanol & 75 & - & 35 \\
\hline & asetonitril & 88 & - & 95 \\
\hline \multirow[t]{3}{*}{ M2 } & aseton & 94 & 97 & 100 \\
\hline & etanol & 82 & 80 & 40 \\
\hline & asetonitril & 95 & 67 & 100 \\
\hline \multirow[t]{2}{*}{ M3 } & aseton & 100 & - & 100 \\
\hline & asetonitril & 100 & - & 100 \\
\hline
\end{tabular}

Tablo 6. M2 örneği için damıtma ve ozonlama+damıtma işlemi geri kazanım miktarları (Recycling amount of M2 samples for distillation and ozonolysis+distillation process)

\begin{tabular}{llll}
\hline Damıtma & Aseton $(\mathrm{mg} / \mathrm{mL})$ & Etanol $(\mathrm{mg} / \mathrm{mL})$ & Asetonitril $(\mathrm{mg} / \mathrm{mL})$ \\
\hline Model çözelti $(150 \mathrm{~mL})$ & 0,90 & 0,05 & 5,50 \\
Birinci örnek $(20 \mathrm{~mL})$ & 6,15 & 0,20 & 36,60 \\
İkinci örnek $(20 \mathrm{~mL})$ & 0,40 & 0,11 & 3,90 \\
Balonda kalan örnek $(110 \mathrm{~mL})$ & 0,004 & 0,007 & 0,11 \\
Ozonlama +damıtma & & & \\
Model çözelti $(150 \mathrm{~mL})$ & 0,90 & 0,05 & 5,5 \\
10 dk ozon & 0,77 & 0,05 & 4,9 \\
Birinci örnek $(20 \mathrm{~mL})$ & 6,2 & 0,3 & 39 \\
Balonda kalan örnek $(130 \mathrm{~mL})$ & 0,05 & 0,01 & 0,32 \\
\hline
\end{tabular}




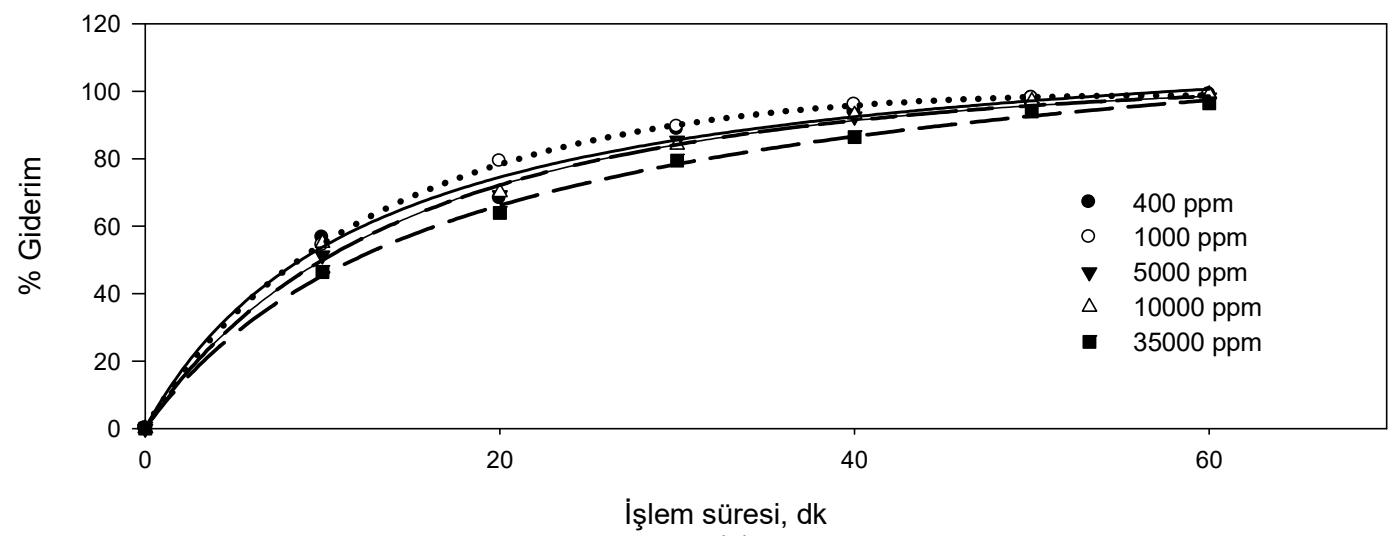

(a)

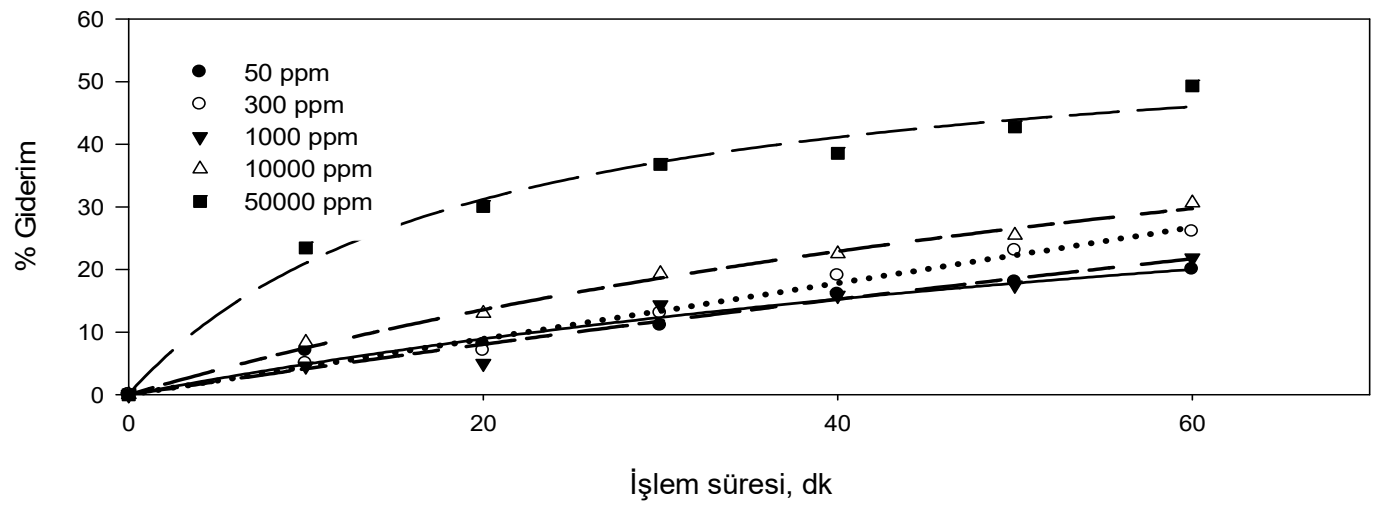

(b)

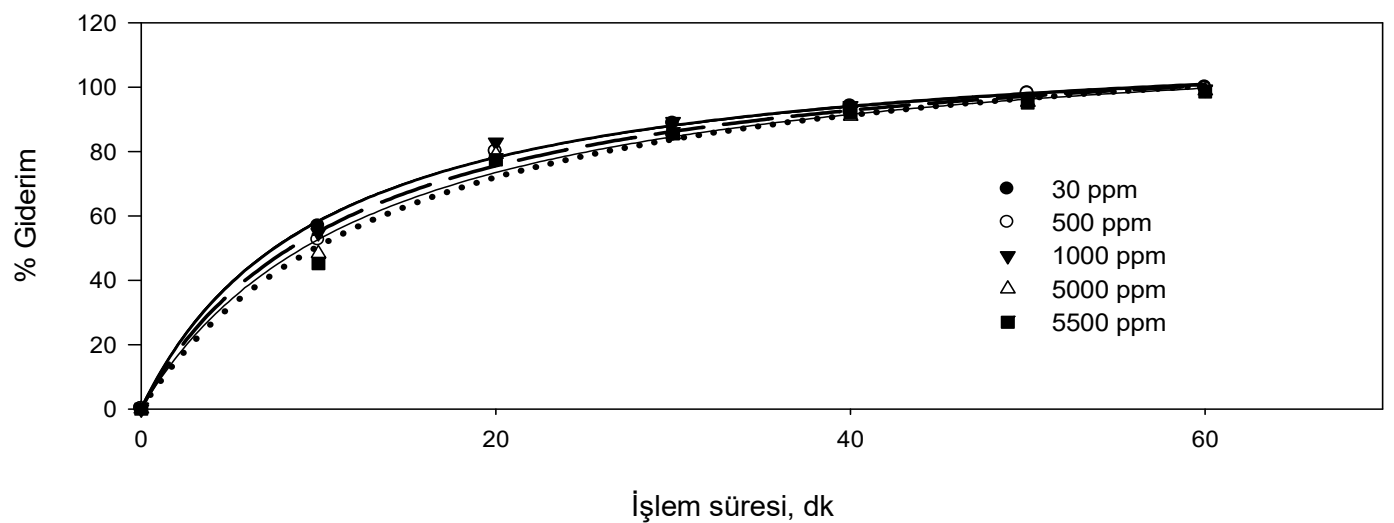

(c)

Şekil 5. Ozonlama+ultrasonikasyon eşanlı işlemi \% giderime derişim ve sürenin etkisi a)Aseton b)Etanol c) Asetonitril (The effect of concentration and time on ozonolysis+ultrasonication process)

Örneklere ultrasonikasyon+damıtma ardışık işlemleri uygulanmış ve \%giderim ve \% geri kazanım oranlarında belirgin bir değişim gözlenmediğinden, ultrasonikasyon işlemi ardından damıtma işlemi uygulamanın avantaj sağlamayacağı sonucuna varılmıştır. Literatür çalışmaları oksidasyon proseslerinin birlikte uygulanmasının organik madde giderimini hızlandırdığını göstermektedir [21]. Bu avantajdan yararlanmak için 1 şınlanmış $\left[{ }^{18} \mathrm{O}\right] \mathrm{H}_{2} \mathrm{O}$ içindeki organik safsızlıkların giderilmesinde ozonlama ve ultrasonikasyon yöntemleri birlikte uygulanmıștır. İlk olarak organik safsızlıkları tek tek içeren model çözeltiler hazırlanmış ve bir saat boyunca ozonlama-ultrasonikasyon eşanlı işlemi uygulanmıştır, sonuçlar Şekil 5'de verilmiştir. Organik maddelerin giderimi tek tek incelendikten sonra üç safsızlığı da içeren model çözeltiler hazırlanmış ve bir saat boyunca ozonlama+ultrasonikasyon eşanlı işlemi uygulanmıştır, sonuçlar Tablo 5'de verilmiştir. Ozonlama+ultrasonikasyon eşanlı işlemi ile organik madde 


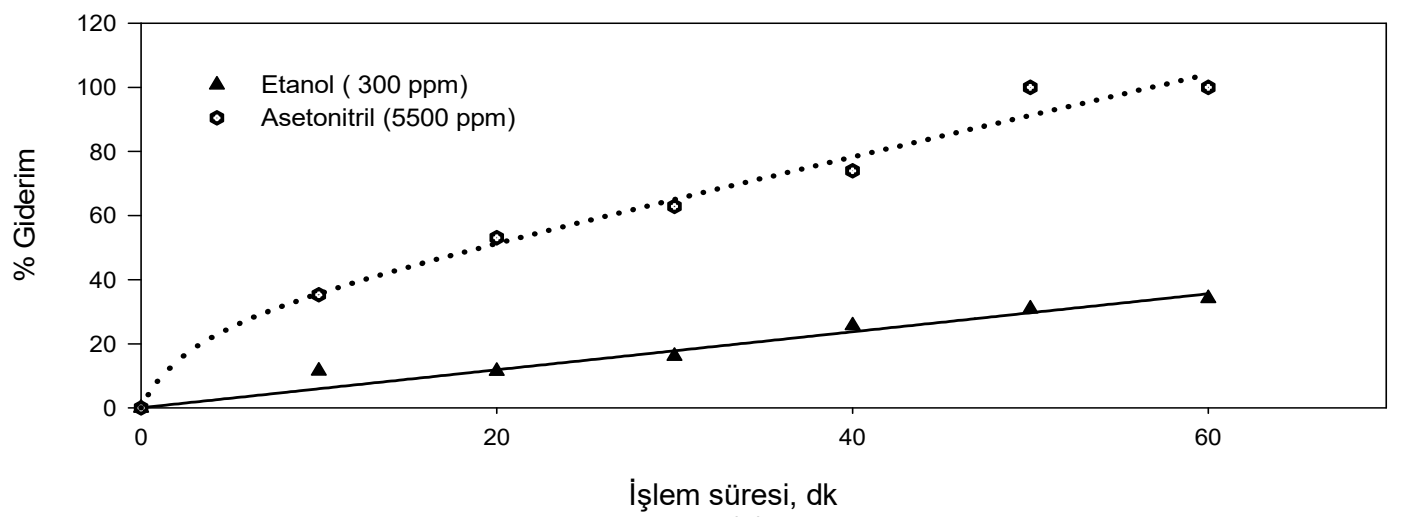

(a)

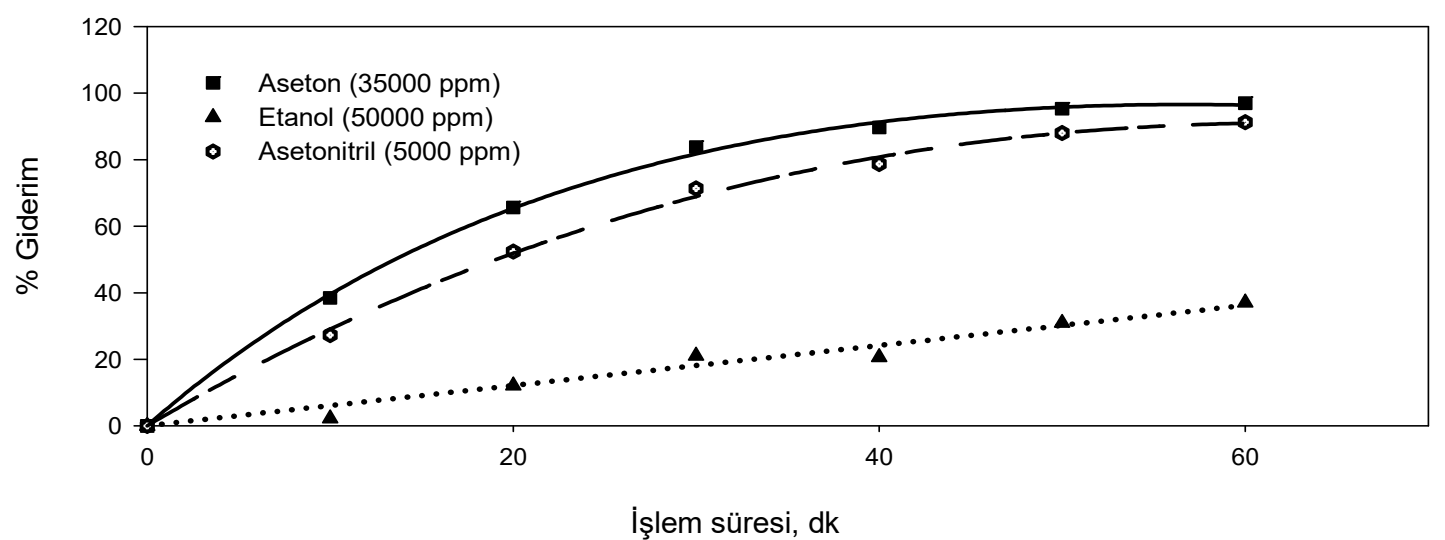

(b)

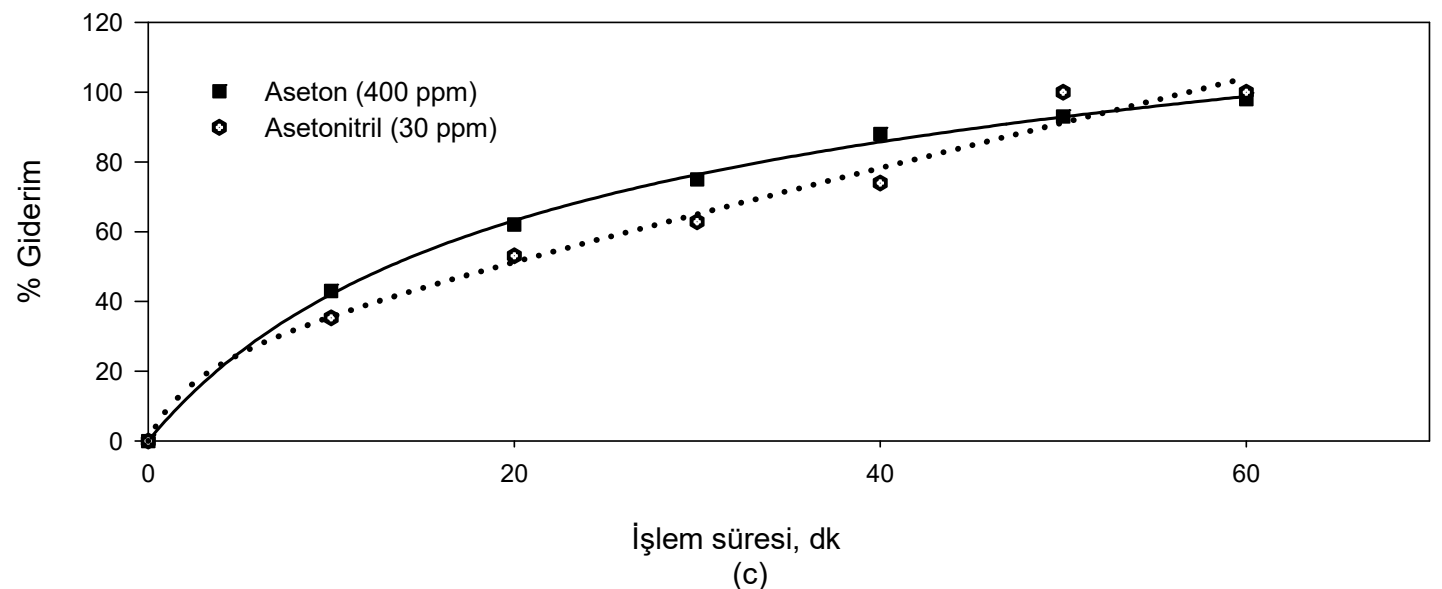

Şekil 6. Işınlanmış $\left[{ }^{18} \mathrm{O}\right] \mathrm{H}_{2} \mathrm{O}$ örneğine ozonlama+ultrasonikasyon eşanlı işleminin uygulaması a) $\mathrm{S} 1$ b) $\mathrm{S} 2$ c) S3 (Aplication of ozonolysis+ultrasonication process at the same time on to irradiated $\left[{ }^{18} \mathrm{O}\right] \mathrm{H}_{2} \mathrm{O}$ sample)

giderimi oldukça yüksektir. Şekil 5 incelendiğinde 1000 ppm derişimindeki çözeltiye $20 \mathrm{dk}$ ozonlamaultrasonikasyon eşanlı işlemi ile asetonun \%80'i giderildiği görülmüştür. Aynı derişimde aseton içeren çözeltiye yalnız ozonlama işlemi (Şekil 1) uygulandığında elde edilen derişim \% 40, yalnız ultrasonikasyon işlemi uygulandığında (Şekil 2) ise giderim \%30 civarlarındadır. Bir saat ozonlama-ultrasonikasyon eşanlı işlemi ile de başlangıç derişimleri yüksek de olsa asetonun tamamının giderildiği belirlenmiştir. Etanol giderimi ise asetona oranla daha yavaştır; ancak işlem süresi arttıkça etanol giderimi de artmaktadır. Ayrıca tek başına ozon ve tek başına ultrasonikasyon yöntemleri ile karşılaştırıldığında ozonlama-ultrasonikasyon eşanlı işlemi ile daha yüksek oranlarda etanol giderimi sağlanmıştır. Tek başına ozonlama işlemi ile 60 dakikada (Şekil 1) etanolun \% 13'ü, sadece ultrasonikasyon işlemi (SSekil 2) ile \%11'i giderilirken, ozonlama-ultrasonikasyon eşanlı işlemi ile bu 
değer \%35 civarındadır. Ozonlama-ultrasonikasyon eşanlı işlemi aseton da olduğu gibi asetonitril için de yüksek oranlarda giderim sağlamıştır. 500 ppm asetonitril içeren çözeltiye 20 dakika işlem uygulandığında asetonitrilin \%80’e yakını giderilmiştir. Aynı derişimde asetonitril içeren çözeltiye tek başına ozonlama işlemi 20 dakika uygulandığında (Şekil 1) giderim \%25, tek başına ultrasonikasyon uygulandığında (Şekil 2) ise \%12 değerlerinde kalmıştır. Üç safsızlığı da içeren model çözeltilerdeki giderimler (Tablo 5) incelendiğinde de aseton ve asetonitrilin gideriminin oldukça yüksek olduğu belirlenmiştir. Etanol gideriminin ise aseton ve asetonitril ile karşılaştırıldığında daha düşük olduğu belirlenmiştir; ancak ozonlama+ultrasonikasyon eşanlı işlem süresi arttıkça etanol giderimi de artmaktadır. $\mathrm{Bu}$ uygulama sonucu oluşan su, \% $\mathrm{O}-18$ miktarını azaltacağı için uygulamadan önce ve sonra kullanılmış $\left[{ }^{18} \mathrm{O}\right] \mathrm{H}_{2} \mathrm{O}$ örneklerine gravimetrik analiz yöntemi uygulanmış ve \%O18 miktarı belirlenmiştir (Tablo 4). Ozonlamaultrasonikasyon süresinin artması ile $\left[{ }^{18} \mathrm{O}\right] \mathrm{H}_{2} \mathrm{O}$ örneklerindeki $\left[{ }^{18} \mathrm{O}\right]$ miktarlarının düştüğü belirlenmiştir. İşlem süresini uzatma organik safsızlıkların \%giderimini artırırken, $\left[{ }^{18} \mathrm{O}\right]$ oranını düşürmesi 1şınlanmış $\left[{ }^{18} \mathrm{O}\right] \mathrm{H}_{2} \mathrm{O}$ nın tekrar kullanılabilirliğini olumsuz etkileyeceğinden 1 saatten fazla uygulanmamıştır.

Sentez cihazından alınarak S1, S2 ve S3 olarak etiketlenmiş 1şınlanmış $\left[{ }^{18} \mathrm{O}\right] \mathrm{H}_{2} \mathrm{O}$ örneklerine ozonlama-ultrasonikasyon eşanlı işlemi uygulanmış ve Şekil 6'da verilmiştir. Şekil 6 incelendiğinde, ozonlama-ultrasonikasyon eşanlı işleminin organik safsızlıkları oldukça etkili bir şekilde giderdiği saptanmıştır. Tek başına ozon ya da tek başına ultrasonikasyon yöntemiyle karşılaştırıldığında ozonlama+ultrasonikasyon eşanlı işlemiyle organik madde giderimi oldukça hızlıdır. Işınlanmış $\left[{ }^{18} \mathrm{O}\right] \mathrm{H}_{2} \mathrm{O}$ örneği içindeki 400 ppm asetonun bir saat ozonlama işlemi ile (Şekil 3c) \%60'1, bir saat ultrasonikasyon işlemi ile (Şekil 4c) 30'u giderilirken, bir saat ozonlama+ultrasonikasyon eşanlı işlemi ile (Şekil 6c) çözelti içindeki asetonun tamamı giderilmiştir. $30 \mathrm{ppm}$ asetonitrilin ise bir saat ozonlama işlemi ile (Şekil 3c) \% 40'1, bir saat ultrasonikasyon işlemi ile (Şekil 4c) \%25'i giderilirken bir saat ozon+ultrasonikasyon işlemi (Şekil 6c) ile tamamı giderilmiştir. Gravimetrik analiz sonuçları incelendiğinde ise \%O-18 miktarındaki düşüş, dört saat ozonlama ve bir saat ultrasonikasyon işlemi sonucunda gerçekleşen düşüşten daha azdır (Tablo 4). Yapılan çalışmalar sonunda en iyi ve en hizlı organik madde gideriminin ozonlama+ultrasonikasyon eşanlı işlemi ile sağlandığı belirlenmiştir. $\mathrm{Bu}$ işlem bir saat süreyle 1şınlanmış $\left[{ }^{18} \mathrm{O}\right] \mathrm{H}_{2} \mathrm{O}$ örneğine uygulanmış ve organik safsızlıklar giderildikten sonra $\left[{ }^{18} \mathrm{~F}\right]$ flor ve $\left[{ }^{18} \mathrm{~F}\right] \mathrm{FDG}$ üretilmiştir. Saflaştırılmış $\left[{ }^{18} \mathrm{O}_{\mathrm{H}_{2}} \mathrm{O}\right.$ içindeki $\%$ O-18 miktarı \%87, etanol miktarı $110 \mathrm{ppm}$ iken aseton ve asetonitrilin tamamen uzaklaştırıldığ 1 belirlenmiştir. Işınlanmış $\left[{ }^{18} \mathrm{O}\right] \mathrm{H}_{2} \mathrm{O}$ içindeki safsılılıklar sentez veriminin düşmesine ve siklotronda basınç yükselmesine neden olabilir [8] .Çalışmamızda saflaştırılan $\left[{ }^{18} \mathrm{O}\right] \mathrm{H}_{2} \mathrm{O}$ ile yapılan üretim sırasında herhangi bir sorun yaşanmamıştır. Saflaştırılan $\left[{ }^{18} \mathrm{O}\right] \mathrm{H}_{2} \mathrm{O}$ ile elde edilen $\left[{ }^{18} \mathrm{~F}\right] \mathrm{FDG}$ verimleri, taze $\left[{ }^{18} \mathrm{O}\right] \mathrm{H}_{2} \mathrm{O}$ ile yapılan üretim verimleri ile karşılaştırılarak Tablo 7'de verilmiştir. Sonuçlardan görüldüğü gibi taze ve saflaştırılmış $\left[{ }^{18} \mathrm{O}\right] \mathrm{H}_{2} \mathrm{O}$ ile yapılan üretim verimleri birbirine oldukça yakındır ( saflaştırılmış ve taze örnek için sirasiyla \%69 ve \%72). Sentezlenen $\left[{ }^{18} \mathrm{~F}\right]$ FDG için kalite kontrol testleri de yapılmış ve sonuçlar Tablo 8'de verilmiştir. Saflaştırılmış $\quad\left[{ }^{18} \mathrm{O}_{\mathrm{H}} \mathrm{O}\right.$ O ile üretilen $\left[{ }^{18} \mathrm{~F}\right]$ FDG'nin spesifikasyonlarının taze $\left[{ }^{18} \mathrm{O}\right] \mathrm{H}_{2} \mathrm{O}$ ile üretilen $\left[{ }^{18} \mathrm{~F}\right]$ FDG spesifikasyon değerlerine uygun olduğu belirlenmiştir.

Tablo 7. Taze ve saflaştırılmış $\left[{ }^{18} \mathrm{O}\right] \mathrm{H}_{2} \mathrm{O}$ ile yapılan üretim verimleri (The yields obtained by fresh and purified $\left[{ }^{18} \mathrm{O}\right] \mathrm{H}_{2} \mathrm{O}$ )

\begin{tabular}{ll}
\hline & {$\left[{ }^{18} \mathrm{~F}\right] \mathrm{FDG}$} \\
\hline Taze $\left[{ }^{18} \mathrm{O}\right] \mathrm{H}_{2} \mathrm{O}$ & $\% 72$ \\
Saflaştırılmış $\left[{ }^{18} \mathrm{O}\right] \mathrm{H}_{2} \mathrm{O}$ & $\% 69$ \\
\hline
\end{tabular}

Tablo 8. Taze $\left[{ }^{18} \mathrm{O}\right] \mathrm{H}_{2} \mathrm{O}$ ve saflaştırılmış $\left[{ }^{18} \mathrm{O}\right] \mathrm{H}_{2} \mathrm{O}$ ile üretilen $\left[{ }^{18} \mathrm{~F}\right] \mathrm{FDG}$ için kalite kontrol verileri (The quality control data for $\left[{ }^{18} \mathrm{~F}\right] \mathrm{FDG}$ produced by fresh and purified $\left[{ }^{18} \mathrm{O}^{\mathrm{O}} \mathrm{H}_{2} \mathrm{O}\right.$ )

\begin{tabular}{|c|c|c|c|}
\hline Test & $\begin{array}{l}\text { Taze }\left[{ }^{18} \mathrm{O}\right] \mathrm{H}_{2} \mathrm{O} \text { ile } \\
\text { üretilen }\left[{ }^{18} \mathrm{~F}\right] \mathrm{FDG}\end{array}$ & $\begin{array}{l}\text { Saflaştırılmış } \\
{\left[{ }^{18} \mathrm{O}\right] \mathrm{H}_{2} \mathrm{O} \text { İle üretilen }} \\
{\left[{ }^{18} \mathrm{~F}\right] \mathrm{FDG}}\end{array}$ & Spesifikasyon \\
\hline $\mathrm{pH}$ & 5,5 & 5,3 & $4,5-8,5$ \\
\hline Radyonüklidik Saflık & $\% 0,00$ & $\% 0,00$ & Değişkenlik $\leq \% 3$ \\
\hline Radyokimyasal Saflık & 98,84 & 98,97 & $\mathrm{FDG} \geq \% 95$ \\
\hline Kimyasal Safsızlıklar & Etanol:42mg/beç & Etanol:36 mg/beç & $\begin{array}{l}\text { Etanol+Aseton: } 50 \mathrm{mg} / \mathrm{bec} \\
\text { Asetonitril: } 4,1 \mathrm{mg} / \mathrm{mL}\end{array}$ \\
\hline Bakteriel Endotoksin & $<175 \mathrm{EU} / \mathrm{beç}$ & $<175 \mathrm{EU} / \mathrm{beç}$ & $<175 \mathrm{EU} / \mathrm{beç}$ \\
\hline
\end{tabular}




\section{SONUÇLAR (CONCLUSIONS)}

Işınlanmış $\left[{ }^{18} \mathrm{O}\right] \mathrm{H}_{2} \mathrm{O}$ 'nun saflaştırılmasında ses ötesi dalgaların tek başına ya da diğer yöntemlerle birleştirilerek ilk kez kullanıldığı bu çalışmada, \% giderimler ve madde kayıpları karşılaştırıldığında en uygun yöntemin ozonlama+ultrasonikasyon eşanlı işlemi olduğuna karar verilmiştir. $\mathrm{Bu}$ yöntemle saflaştırılan $\left[{ }^{18} \mathrm{O}\right] \mathrm{H}_{2} \mathrm{O}$ kullanılarak üretilen $\left[{ }^{18} \mathrm{~F}\right] \mathrm{FDG}$ verimi \% 69 olarak gerçekleşirken taze $\left[{ }^{18} \mathrm{O}\right] \mathrm{H}_{2} \mathrm{O}$ ile yapilan üretimde $\left[{ }^{18} \mathrm{~F}\right] \mathrm{FDG}$ verimi $\% 72$ olmuştur. Sonuç olarak uygulanan yöntem ile, ışınlanmış $\left[{ }^{18} \mathrm{O}\right] \mathrm{H}_{2} \mathrm{O}$ içindeki safsızlıklar giderilerek tekrar kullanılabileceği belirlenmiştir.

\section{TEŞEKKÜR (ACKNOWLEDGEMENT)}

$\mathrm{Bu}$ çalışmada 1şınlanmış $\left[{ }^{18} \mathrm{O}\right] \mathrm{H}_{2} \mathrm{O}$ örnekleri EczacıbaşıMonrol Nükleer Ürünler A.Ş.' den temin edilmiştir. Desteklerinden ötürü yazarlar Eczacıbaşı-Monrol Nükleer Ürünler A.Ş’ye teşekkür eder.

\section{KAYNAKLAR (REFERENCES)}

1. 1 .Fowler J.S., Volkow N.D., Molecular imaging: Positron Emission Tomography Springer ScienceBusiness Media, New York, 2016.

2. Moon W., Oh S., Cheon J., Chae W., Simple purification of recovered $\left[{ }^{18} \mathrm{O}^{1} \mathrm{H}_{2} \mathrm{O}\right.$ by $\mathrm{UV}$, ozone and solid-phase extraction methods, Applied Radiation and Isotopes, 65 (6), 635-40, 2007.

3. Fawdry R.M., A simple effective method for estimating the $\left[{ }^{18} \mathrm{O}\right]$ enrichment of water mixtures, Applied Radiation and Isotopes, 60, 23-26, 2004.

4. Kitano H., Magata Y., Tanaka A., Muka1 T,. Performance assessment of O-18 water purifier, Annals of Nuclear Medicine, 15 (1), 75-78, 2001.

5. Nishijima K., Kugea Y., Tsukamotob E., Sekic K., Increased $\left[{ }^{18} \mathrm{~F}\right] 2$-fluoro-deoxy-d-glucose $\left(\left[{ }^{18} \mathrm{~F}\right] \mathrm{FDG}\right)$ yield with recycled target $\left[{ }^{18} \mathrm{O}\right]$ water: factors affecting the $\left[{ }^{18} \mathrm{~F}\right] \mathrm{FDG}$ yield, Applied Radiation and Isotopes, 57, 43-39, 2002.

6. Ito S., Sakane H., Deji S., Saze T., Radioactive byproducts in $\left[{ }^{18} \mathrm{O}\right] \mathrm{H}_{2} \mathrm{O}$ used to produce ${ }^{18} \mathrm{~F}$ for $\left[{ }^{18} \mathrm{~F}\right] \mathrm{FDG}$ synthesis, Applied Radiation and Isotopes, 64, 298-305, 2006.

7. Razpotnik P., Tarsic J., Veber M., Novic M., Efficiency and characteristic of solid-phase (ionexchange) extrraction for removal of $\mathrm{Cl}$ - matrix, Issue series tittle J.Cromotography A, 999 (1), 23-29, 2003.

8. Asti M., Grassi E., Sghedoni R., De Pietri G., Purification by ozonolysis of ${ }^{18} \mathrm{O}$ enriched water after cyclotron 1rradiation and the utilization of the purified water for the purification $\left[{ }^{18} \mathrm{~F}\right] \mathrm{FDG}$, Applied Radiation and Isotopes, 65, 831-835, 2007.

9. Berridge M.S., Kjellström R., Design and use of silver targets for $\left[{ }^{18} \mathrm{~F}\right]$ flouride production, Applied Radiation and Isotopes, 50, 699-705, 1999.
10. Weber K., Marx H., Vierling J., Wittstadt U., Eisenhut M., Electrolytic purification of $\left[{ }^{18} \mathrm{O}\right]$ water. J. Labeled, Compounds Radio-Pharmaceuticals, 46 (1) S279, 2003.

11. Mangner T.J., Mulholland G.K., Toorongian S.A., Jewett D.M., Kilbourn M.R., Purification of used O-18 target water by photochemical combustion, Journal of Nuclear Medicine, 33, 982-983, 1992.

12. Hernandez R., Zappi M., Colucci J., Jones R., Comparing the performance of various advanced oxidation processes for treatment of contaminated water, Journal of Hazardous Materials, 92, 33-50, 2002.

13. Gökkuş Ö., Çiner F., Investigation of color and cod removal from wastewater containing disperse yellow 119 and disperse red 167 using fenton oxidation process, Journal of the Faculty of Engineering and Architecture o Gazi University, 25 (1), 49-55, 2010.

14. Jyothi K.P., Yesodharan S., Yesodharan E.P., Ultrasound US), Ultraviolet light (UV) and combination (US+UV) assisted semiconductor catalysed degradation of organic pollutants in water: Oscillation in the concentration of hydrogen peroxide formed in situ, 21, 1787-1796, 2014.

15. Suzuki H., Araki S., Yamamota H., Evaluation of advanced oxidation processes (AOP) using $\mathrm{O}_{3}, \mathrm{UV}$ and $\mathrm{TiO}_{2}$ for degradation of phenol in water, Journal of Water Process Engineering, 7, 54-60, 2015.

16. He L.L., Liu X.P., Wang Y.X., Wang Z.X., Yang Y.J., Gao Y.P., Sonochemical degradation of methyl orange in the presence of $\mathrm{Bi}_{2} \mathrm{WO}_{6}$ : Effect of operating parameters and the generated reactive oxygen species, Ultrasonic Sonochemistry, 33, 90-98, 2016.

17. Tran N., Drogui, P., Brar S.K., Sonochemical techniques to degrade pharmaceutical organic pollutants, Environmental Chemistry Letters, 13, 251268, 2015.

18. Jyothi K.P., Yesodharan S., Yesodharan E.P., Ultrasound (US), Ultraviolet light (UV) and combination (US + UV) assisted semiconductor catalysed degradation of organic pollutants in water: Oscillation in the concentration of hydrogen peroxide formed in situ, Ultrasonic Sonochemistry, 21, 17871796, 2014.

19. Harichandran G., Prasad S., Sonofenton degradation of an azo dye, direct red, Ultrasonic Sonochemistry, 29, 178-185, 2016.

20. Onuki S., Koziel J.A., Jenks W.S., Cai L., Rice S., Leeuwen J.H., Ethanol purification with ozonation, activated carbon adsorption and gas stripping, Separation and Purification Technology, 151, 165-171, 2015.

21. Naffrechoux E., Chanoux S.Petrier C., Suptil J., Sonochemical and photochemical oxidation of organic matter, Ultrasonics Sonochemistry, 7, 255-259, 2000. 
